\title{
Methodological insights on measurement and evaluation of compulsive buying behavior among young consumers in Poland: the case of compulsive- and non-compulsive buyers
}

\author{
Piotr Tarka ${ }^{1}$ D . Jasurbek Babaev ${ }^{2}$
}

Accepted: 28 October 2020 / Published online: 18 November 2020

(C) The Author(s) 2020

\begin{abstract}
In this study we focused on the methodological insights, the measurement and evaluation of compulsive buying tendencies among young consumers in Poland. We administered the Compulsive Buying Scale (CBS) developed by d'Astous et al. (in: Goldberg, Gorn, Pollay (eds) Advances in consumer research, Association for Consumer Research, Provo, 1990) for North America and adapted it to the Polish population. Then used the data to develop a Polish version of the Compulsive Buying Scale (P-CBS). The study extended previous methodological work on new consumers' culture, and more importantly, investigated the compulsive buying in two groups of consumers: compulsive- and non-compulsive buyers. The sample comprised 504 young Polish citizens, aged between 17 and 25 years. In the complex analytical process, we replicated the three-dimensional structure of the CBS scale (d'Astous et al. 1990): the 'Tendency to Spend', a 'Reactive Aspect' of compulsive buying, and 'Post Purchase Guilt'. This process included the following steps: the translation of the items, an exploratory and confirmatory factor analysis, based on latent variables theory, and a reliability and validity analysis. Data analyses indicated a satisfactory reliability and validity of the P-CBS. Research findings are presented across the sample and the subsamples of compulsive buyers and non-compulsive buyers.
\end{abstract}

Keywords Compulsive buyers and noncompulsive buyers · Compulsive buying scale (d'astous et al. 1990) · Young consumers · Eastern European culture and consumption

Piotr Tarka

piotr.tarka@ue.poznan.pl

1 Department of Market Research, Poznan University of Economics and Business, Al. Niepodległości 10, 61-875, Poznań, Poland

2 Vistula University, Warszawa, Poland 


\section{Introduction}

Scholars around the world differ in their methods of understanding compulsive buying behavior as a market phenomenon. For instance, Kraepelin (1915) described compulsive buying with the term 'oniomania', while Bleuler (1924) referred to it as 'buying mania'. The latter believed that compulsive buying reflects the uncontrollable urges that repeatedly compel an individual to make purchases, bringing temporary relief from psychological needs. After buying, individuals often feel guilty about succumbing to their urges and in turn suffer from social and financial harms (see also Faber et al. 1987; McElroy et al. 1994; Manolis and Roberts 2012; Khare 2013). These harms lead to negative consequences in individuals' lives, such as sizeable consumer debts, broken families, and a generally heightened level of distress (see Dittmar 2005; Lo and Harvey 2011; Baker et al. 2016).

Compulsive buying behavior, according to O'Guinn and Faber (1989, pp. 148), represents "... a response to an uncontrollable drive or desire to obtain, use, or experience a feeling, substance, or activity that leads an individual to repetitively engage in a behavior that will ultimately cause harm to the individual and/or to others." Note that in the literature on consumer research, this phenomenon was also defined as compulsive consumption or compulsive buying (Faber et al. 1987; see Table 1). Only occasionally, it was defined as addictive consumption (Elliott 1994; Tomer 2001).

Overall, the compulsive buying reflects the irresistible desire to purchase products and a sudden drop in psychological tension after a purchase, accompanied by a feeling of relief (see Mueller et al. 2011). Note, however, that compulsive buying is qualitatively different from impulsive or standard buying behavior, for it provides the consumer a short-term pleasure, some sort of gratification, rather than a long-term satisfaction. Thus, compulsive buyers do not derive benefits from a purchased product. Instead, they experience shortlived delights during the buying process itself, followed by negative consequences such as regretting the purchase (O'Guinn and Faber 1989). McElroy et al. (1994) characterized compulsive buying as a maladaptive preoccupation with making purchases, and one characteristic of compulsive buying is that the purchased products are often not used or needed at all.

Interestingly, compulsive buyers experience both recurring acts and thoughts of problematic buying, what often causes emotional distress and negative emotions such as guilt, shame and regret (Ridgway et al. 2008; Cicognani 2011). Besides, compulsive buying trends flourish in societies, cultures, and groups of individuals which have deficits in selfcontrol. Some but not all studies find a stronger propensity towards compulsive buying in females than in males (Schlosser et al. 1994; Dittmar 2005; Reisch and Neuner 2002; Mueller et al. 2011; Roberts and Roberts 2012). Compulsive buying trends grow primarily in societies in which people suffer from anxiety, depression, alienation, low self-esteem, and excessive materialistic orientation (see Scherhorn et al. 1990; Yurchisin and Johnson 2004, Mueller et al. 2010; Neuner et al. 2005).

Although compulsive buying appears to be commonly accepted in well-developed countries, mostly Western cultures (Scherhorn et al. 1990, 1992; Koran et al. 2006), it appears that it also grows rapidly in developing economies and Eastern cultures (Boski 1992; Hofstede 2001; Horváth et al. 2013; Tarka and Kukar-Kinney 2020). However, despite the increasing importance of this phenomenon, there are still only a few studies that focused on very specific aspects of measurement and diagnosis of compulsive buying in Poland, that would comprise wider methodological and substantive contexts. For instance, the study of Tarka and Kukar-Kinney (2020) explored compulsive buying only on a very general 


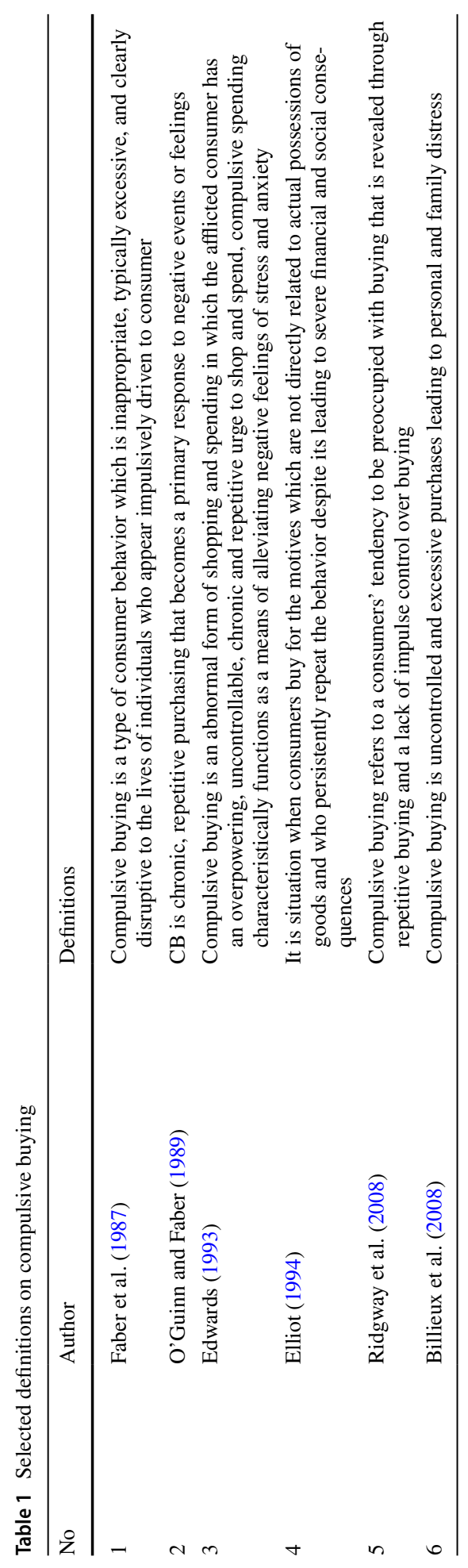


level - total sample of young adults, without distinguishing between groups of consumers (i.e., compulsive buyers and non-compulsive buyers), despite the fact that a strong and generalized urge to buy can characterize all consumers at different levels, and most likely, at different times (see d'Astous and Bellemare 1989; d'Astous 1990). For this reason, less extreme forms of compulsive buying behavior are also worth studying. And this is what the present study intended to do.

Further, although the literature on compulsive buying reports many other scales that allow to measure this phenomenon as for instance, the Clinical Screener (Faber and O’Guinn 1992), Questionnaire About Buying Behavior (QABB; Lejoyeux and Ades 1994; Lejoyeux et al. 2007), the Richmond Compulsive Buying Scale (RCBS; Ridgway et al. 2008) along with its Polish version (Tarka and Kukar-Kinney 2020), as well Pathological Buying Screener (Müller et al. 2015) and Compulsive Buying Indicator (Raab et al. 2005) - both based on German samples; we focused on the scale developed by d'Astous et al. (1990). The reason for selecting, administering and exploring this scale was that it was developed and validated by d'Astous et al. (1990) with purpose of measuring compulsive buying in younger populations. In this sense, we provided a version of the Compulsive Buying Scale that was validated for young Polish consumers. We claim that this scale will be beneficial both for researchers and for other groups in applied contexts, as for instance public policy decision makers. The latter could use data collected through this scale to take preventive actions to stop a further proliferation of unwanted compulsive buying among the youth (see Keeley and Buehler 2016). We also argue that a validated version of this scale can be administered in Eastern European cultures in general.

The structure of this article is as follows. First, we review the existing literature on compulsive buying, particularly referring to research in matured and developing countries (e.g., Neuner et al. 2005; Mueller et al. 2010; Hubert et al. 2014; Singh and Nayak 2015; Lam et al. 2018). We also discuss how social pressure to buy consumer products might influence young consumers living in Poland. Note that the same social pressure is also felt by young people in other countries, e.g., in Hungary (see Horváth, van Herk and Adigüzel 2013). Afterwards, we present research methods, followed by a discussion of our results on compulsive buying and its links to related concepts in our sample of young Polish consumers. We assess the quality of the overall scale and the psychometric qualities of each item. Further, we present the findings on the reliability and validity of the theoretical constructs (i.e., the three factors underlying the adapted version of the CBS: 'Tendency to Spend', the 'Reactive Aspect', and 'Post Purchase Guilt'). Note that the results are consistently reported both in the context of the total sample and separately for compulsive buyers and non-compulsive buyers. Finally, we discuss the findings, the theoretical contribution of the present study, suggest practical implications of our findings and end with the limitations.

\section{Literature review}

\subsection{Prior studies on compulsive buying in matured and developing countries such as Poland}

Compulsive buying typically occurs in matured, but also in developing economies and societies (Neuner et al. 2005). Past research has regularly referred to mainstream 'Western industrial societies' and countries such as: Germany (e.g., Scherhorn et al. 1990, 1992), the UK (e.g., Dittmar 2005; Elliott 1994), France (e.g., Lejoyeux et al. 1995), 
Australia (e.g., Lyons and Henderson 2000); Spain (e.g., Otero-López and Villardefrancos 2014), Denmark (e.g., Hubert et al. 2014), USA (e.g., Faber and O'Guinn 1989; O'Guinn and Faber 1989; McElroy et al. 1994; Roberts and Jones 2001; Koran et al. 2006), and Canada (e.g., Valence et al. 1988; d'Astous and Bellemare 1989; d'Astous 1990).

Note that studies conducted in the US implied that approximately 18 million Americans were 'addicted to compulsive consumption' (Workman and Paper 2013). Also, the prevalence rate of compulsive buying in the US was observed to be higher among young people (e.g., college students and adolescents) than in adults (Roberts 2000; Roberts and Jones 2001; Roberts and Roberts 2012; Yurchisin and Johnson 2004; Maraz et al. 2016). Similar trends were also discernible in many developing and less affluent countries (Ger and Belk 1996) whenever consumers were confronted with influences of Western consumer culture, market trends, wealthy neighborhoods, and economy system based on capitalism (Varman and Vikas 2007; Ritzer and Jurgenson 2010; Zhang 2018). This is especially the case when poor countries experienced economic growth followed by social and cultural transitions (Belk 1999; Ibroscheva 2012; He et al. 2017). For instance, in China (Li et al. 2014), 7\% of the population is claimed to be addicted to buying, though the people living there differ somewhat in compulsive buying from individuals in Western cultures.

In consumer-driven economies (O'Shaughnessy and O'Shaughnessy 2002), people utilize the symbolic value of certain goods to signal a positive personal or social identity to others (Yurchisin and Johnson 2004; Lim and Ang 2008; Lu et al. 2016; Zhang et al. 2014). Simply put, due to the need for social comparisons between consumers within a society, individuals are motivated to impress other members of their society by engaging in a more attractive living style and investing in perceived personal well-being. This impression builds on buying certain (luxury) products, and in a more general sense, the possession of all kinds of material things (Mick et al. 2004; Vihalemm and Keller 2011; Cloutier 2015). The problem is that in such societies, these aspirations often lead to an increase of compulsive buying and shopping addiction.

For Poland, it can be postulated that the economic and social changes in recent decades, i.e., the transitioning from a Communist system to a free market, the awareness of globalization trends and the desire for buying products from other countries (Baack and Boggs 2008; Kozminski 1991/1992; Luthar 2006; Mazurek and Hilton 2007) gave a significant rise to consumer trends and compulsive buying (Tarka and Kukar-Kinney 2020). Polish consumers were suddenly exposed to an unprecedented volume and variety of products that they were not familiar with. When the desired economic transition took place, Polish consumers could finally satisfy their pent-up needs, whether they could afford it or not (Tobacyk et al. 2011; Zalewska 2016). The problem was that most Poles were ill-prepared for the challenges of an affluent society (Mazurek and Hilton 2007). This resulted in frustration, disappointment, feelings of alienation, insecurity, and reduced self-esteem (Ger and Belk 1996).

One should also consider that Polish culture is characterized by collectivistic values. Specifically, a high level of cultural and ethnic homogeneity, collective valuing, and developing and maintaining close personal bonds (Boski 1992, 2006). Paradoxically, this cultural orientation may foster compulsive buying tendencies because people naturally want to buy products, but even more so they want social approval and admiration of other members of their community and society. People might believe that they get the admiration of others by buying all kinds of products that a person does not really need, but that were supposed to indicate a certain social status. Researchers such as d'Astous (1990) pointed to the potential link between compulsive buying and a susceptibility to social influence. Thus, 
living in close socio-cultural relationships can make people in Poland prone to compulsive buying.

\subsection{Compulsive buying tendencies among young consumers}

In this study, we focused on the examination of compulsive buying tendencies in Poland. We were primarily interested on the investigation of young consumers and less so on older people. The reason for this prediction was that previous studies (e.g., O'Guinn and Faber 1989; d'Astous et al. 1990; Dittmar 2005) observed that compulsive buying occurs more often among younger people (around the age of 18 years) than adults. Thus, it typically begins in late adolescence (Schlosser et al. 1994; Dittmar 2005), although some researchers even stated that compulsive buying is evident even in earlier life, when young people are more prone to addictive behavior in general. In adolescence, many orientations and abilities are being formed (Larson 2001). Adolescence is a period with transitions that include biological, social, and psychological changes (Byrne et al. 2007). Consequently, young people might be especially vulnerable to compulsive buying, for instance because they want social approval from their peers when they buy the newest smartphone or clothes from an expensive brand.

Since individuals with compulsive buying tendencies are often reported to show excessive shopping behavior, especially when they feel under pressure or stressed, we maintain that young adults might try to compensate for familial or non-familial distress by purchasing (see Roberts and Roberts 2012; Johnson et al. 2001). This argument also fits with the observation by d'Astous (1990) that compulsive buyers seem to be more anxious in general and more likely to have family members who are also plagued by addictive behavior such as alcoholism, toxicomania, or bulimia.

Previous research that explored the familial influence on compulsive buying also found that this type of behavior is derived from parents' values, attitudes, and behavior (Elliott 1994), and is often rooted in early life experiences (Grougiou et al. 2015). In one's early life, a parent represents the most important agent in young consumers' socialization, and therefore plays the most important role in the creation of a young person's values and behavior (Grougiou and Moschis 2015). Children quickly acquire values and skills by imitating their parents' decision-making styles (Elliot 1994). Thus, family problems might influence adolescents' compulsive buying dispositions. Family conflicts, troubles, or disorders are potential explanatory factors for adolescents' compulsive consumption tendencies. The same is true for financial behavior, i.e., the improper use of credit cards (Elliot 1994; Khare 2013). Parents play an important role in the establishment of the financial identity of adolescents and are responsible for supporting the materialistic values (Chitakunye and Maclaran 2012), which in turn foster unwanted compulsive buying behaviors (Richins and Chaplin 2015).

Besides familial influences, young consumers' proneness to compulsive buying is also impacted by other aspects (see Hampel and Peterman, 2006) and personal problems (d'Astous et al. 1990). For instance, Byrne et al. (2007) identified the following factors as stressors in adolescent life: peer pressure, love-romantic relationships, and school problems. The link between stress and compulsive buying appears to be the same for both genders. Yet if one concentrates on compulsive buying, females in their adolescence seem to have more problems with this behavior than males (see Claes et al. 2010). However, evidence on gender effects is rather mixed. 


\section{Present research}

We adapted the CBS by d'Astous et al. (1990) in a way that it could be applied in the Polish culture and fitted to Polish living conditions. Then, we administered this scale in a sample of young Polish consumers in order to diagnose their compulsive buying tendencies. We were specifically interested in the consumer behavior of two groups, compulsive- and noncompulsive buyers. We tried to answer the following question: (1) Does the translated and slightly modified version of the scale have methodologically the same or similar dimensions as the original CBS has? Note that the three dimensions of the original scale were the following: 'Reactive Aspect-RA', 'Tendency to Spend Money-TTSM', and 'Post-purchase Guilt-PPG'. Other questions to be answered were: (2) Are the psychometric criteria acceptable in the adapted version of the scale? And (3), did the factor loadings of the items indicate the same, or at least approximately the same, structure as the previously described dimensions of the scale ('Reactive Aspect-RA', 'Tendency to Spend Money-TTSM', and 'Post-purchase Guilt-PPG'; see D'Astous et al. 1990)? The final question was, (4) To what extent does the Polish scale-CBS yields the same or different results as the original scale in two groups of young (i.e., compulsive vs. non-compulsive buyers)?

In other words, we claim that the translated and adapted version of the scale (named "Polish-Compulsive Buying"; P-CBS), as compared to its original version (CBS; see d'Astous, et al. 1990), might result in the same (see above: RA, TTSM, PPG) or different structure and dimensions when being administered in Poland. Also note that we intended to explore whether this scale shows a different pattern of results in the entire sample as compared to the subsamples of compulsive and non-compulsive buyers. In this regard, we followed the idea of d'Astous and Tremblay (1989) who argued that there are individual differences in the urge to buy. We claimed that even less extreme forms of compulsive buying behavior are worth being investigated because average consumers may show at least some degree of vulnerability towards compulsive buying or are even in an early stage of developing compulsive buying tendencies and are not aware of it. In other words, compulsive behavior might also be observed in a group of average consumers. Consequently, we administered the P-CBS in a sample of young Polish consumers without pre-selecting them based on their consumer behavior so that we could expect representation of the whole spectrum of buying behavior, e.g., from buying behavior that does not show any compulsive tendencies to extreme cases of compulsive buying. We also argued that the P-CBS would validly measure individual differences between buyers, with a special focus on their potential compulsive behavior tendencies. The reason was that this scale was originally developed to measure extreme buying behavior, and not average shopping behavior (d'Astous et al. 1990).

Further, the P-CBS was tested in a sample of Polish consumers (aged between 17 and 25 years). This was done because we claimed that the processes of economic transition and acculturation that have taken place in Poland during the past decades has led to a situation in which the frequency of compulsive buying might match that of Western cultures. In other words, given the large-scale socioeconomic and cultural transitions that Poland has undergone since the fall of the Communist system and the development of a free market that stimulated economic growth, many young consumers were expected to show signs of compulsive buying behavior (see Eurostat data in 2019 for period of 2016-2018).

Finally, the validity of the P-CBS scale was tested on the basis of correlations with the Clinical Screener (CS; Faber and O'Guinn 1992) and some other variables supposed to indicate buying behavior and problems with spending too much money (i.e., self-reported 
buying and spending behavior; see below). The CS (Faber and O'Guinn 1992) measured the following aspects of compulsive buying: lack of control, distress at the thought of others' knowledge of the person's spending patterns, the tension felt when not buying something, and the use of buying to feel better. Also note that the CS (Faber and O'Guinn 1992) represented an alternative instrument to measure compulsive buying among the youth.

Given the above arguments and objectives, we proposed the following hypotheses:

A1 Young compulsive Polish buyers versus non-compulsive young buyers respond differently to the three dimensions of the compulsive buying scale. Consequently, both groups will differ in terms of metric and scalar invariance of the P-CBS.

A2a The P-CBS scale, administered in compulsive buyers, indicates a high level of coherence within the structure of the measurement model (CFA) and a high reliability within each of its three expected factors (RA, TTSM, and PPG).

A2b The P-CBS, administered within non-compulsive buyers, indicates a low level of coherence within the structure of the measurement model (CFA) and low reliability within each of the three expected factors (RA, TTSM, and PPG).

A3a In compulsive buyers, the P-CBS scale indicates strong correlations with the 'Clinical Screener' (CS Faber and O'Guinn 1992) and variables measuring the 'self-reported buying and spending behavior' of consumers. Strong correlations prove the validity of the P-CBS scale.

A3b In non-compulsive buyers the P-RCBS scale shows low correlations with the CS (Faber and O'Guinn 1992) and the constructs of 'Self-reported buying and spending behavior'. Hence, the P-CBS will be less valid in non-compulsive buyers as compared to compulsive buyers.

\section{The compulsive buying scale by d'Astous et al. (1990)}

As noted, in this study we focus on adaption of the CBS (d'Astous et al. 1990) to Polish culture and life circumstances, although the items of the original CBS scale, capturing the multifaceted nature of compulsive buying, were developed by Valence et al. (1988) and d'Astous and Tremblay (1989), and later modified for surveys in samples of adolescents. According to the factor and content analyses of the CBS (conducted by Valence et al. 1988, d'Astous and Tremblay, 1989), three interrelated factors were found: 'Reactive AspectRA', 'Tendency to Spend Money-TTSM', and 'Post-purchase Guilt-PPG'. The first factor consisted of four items (e.g., "Shopping is a way of relaxing and forgetting my problems"); the second factor was measured by five items (e.g., "When I have money, I cannot help but spend part or all of it"), while the third factor included three items (e.g., "At times, I have felt somewhat guilty after buying something because it seemed unreasonable").

Note that the first factor 'RA', corresponded to stress in daily family life and measures of shopping behavior as a coping strategy (i.e., to relax). This factor also measures the tendency to be 'reactive' (Valence et al., 1988). It captures the sudden irresistible urge to go shopping, and the strong urge to buy something. The second factor 'TTSM' in Valence et al., (1988; see also d'Astous and Tremblay 1989) was defined in terms of irrational 
behavior of a consumer and the consumer's impulsiveness in buying behavior. While the third factor of the scale, 'PPG', measures the fear that compulsive consumers often feel after a purchase and/or generally irrational buying behavior. It is also noteworthy that Valence et al. (1988) at the beginning of their research, identified fourth dimension of compulsive buying - 'the family environment', however, after some improvements of the scale, this dimension was dropped.

Finally, the whole instrument was adjusted by d'Astous et al. (1990) for being used in samples of young adults (see also Cole and Sherrell 1995). However, one item as part of 'PPG' construct was eliminated due to lack of clarity ("I have sometimes thought-If I had to do it over again, I would...- and felt sorry for something I have done or said), while the other items were re-worded to enhance understandability. This modified version of the scale, comprising of eleven items (see d'Astous et al. 1990) considerably improved its validity and enhanced its easiness in understanding the problem of compulsive buying among the youth.

\section{Procedure}

\subsection{Participants and design}

The sample included young consumers at universities, high schools, and professional schools in Poland. We choose to focus on young consumers because we assumed that they were more prone to compulsive buying than older people (see O'Guinn and Faber 1989; d'Astous et al. 1990; Schlosser et al. 1994; Roberts and Jones 2001; Joireman et al. 2010; Palan et al. 2014). Furthermore, they should be more open to new ideas and creating social trends but are also vulnerable towards market trends. Hence, it was important to test young consumers' vulnerability to compulsive buying behavior in the hope of shedding new light onto this problem (see Blackwell et al. 2001; Hill et al. 2001; Grougiou and Moschis 2015). In this context, the selection and adaption of instrument for the present study (that was adjusted deliberately by d'Astous et al. 1990 to diagnose the compulsive buying phenomenon among the youth representatives), gains even more importance.

The first group of participants were drawn from universities' pools of students. They were recruited randomly by using a database of all registered students at bachelor and master-level. Students from high schools were recruited from the 10th to the 12th grades, while in professional schools, participants from the 11th and the 12th grades were recruited. All schools and universities were geographically dispersed across Poland. The process of participant recruitment was as follows. First, we contacted the respective school representatives (e.g., a director, schoolteacher, and professor in the case of recruiting university students). After receiving permission to conduct a survey, ${ }^{1}$ we delivered the set of questionnaires to the randomly selected participants of that institution (e.g., high school). For data collection, researchers attended each class to explain the subject and objectives of the research to the participants and the teacher or director of the high school. Moreover, we explained how the questions could be answered by demonstrating the response scales. We therefore could ensure that the entire study was carried out properly and that the data were

\footnotetext{
1 From the youngest respondents, aged 17, we received parental consent organized by a high school director or the teacher of a class.
} 
of high quality. In the end, the sample size in the empirical study equalled $\mathrm{N}=504$ participants. Data were collected between September and October 2018. Nearly two-thirds (65\%) of our participants were females. The mean age of the entire sample was 20 years, with the youngest participants being 17 years and the oldest being 25 years old. Less than half of the participants (40\%) were students of professional schools. The other participants were high school students (34\%) and university students (26\%). 68\% of the participants lived together with both parents and had siblings (i.e., 1 brother/sister, 43\%; 2 brothers/sisters, $27 \%, 3$ brothers/sisters, $6 \%$, and more than 3 brothers/sisters, $4 \%$ ).

\subsection{Sub-groups of participants: compulsive and non-compulsive buyers}

Since we were interested in how the two groups of participants would respond on the P-CBS scale, we categorized all students either into compulsive or non-compulsive buyers. For this purpose, we applied the Clinical Screener (CS; Faber and O'Guinn 1992). Participants were split into compulsive and non-compulsive consumers based on Faber and O'Guinn's (1992) guidelines described in the CS. The total CS score was calculated on the basis of seven items (CS1-CS7) by computing the following regression parameters: CS total $=-9.69+(\mathrm{CS} 10.33)+(\mathrm{CS} 20.34)+(\mathrm{CS} 30.50)+(\mathrm{CS} 40.47)+(\mathrm{CS} 50.33)+(\mathrm{CS} 6$ $0.38)+(\operatorname{CS} 7$ 0.31 $)$. An individual was assessed according to this equation on her or his answers on 5-point scales. Each response scale ranged from 1 (indicating very frequent compulsive buying behavior) to 5 (indicating the complete absence of compulsive buying behavior). A cut-off point was set at the level $\leq-1.34$, meaning that a student who scored less than -1.34 was categorized as a compulsive buyer. In the case that a participant's score was above this cut-off point, he/she was categorized as a non-compulsive buyer. This strategy was often used to categorize compulsive and non-compulsive buyers in European samples (e.g., Scherhorn et al. 1990; Mueller et al. 2015).

\subsection{Research methods}

The adaption process of the CBS to Polish samples included two steps. In Step 1, we translated the original version of the scale from English to Polish and tested the ease of its comprehension (called "Polish-Consumer Buying Scale"; P-CBS) and the quality of its translation.

In Step 2, we examined the psychometric properties of the P-CBS scale. We used the data collected in a cross-sectional study in Poland (see above). Data analyses were first run for the entire sample, and then separately for participants identified as compulsive or non-compulsive buyers. All analyses relied on the latent variables' measurement theory. Specifically, we explored the structure and consistency of the analyzed latent variables (the 'Reactive Aspect'-RA, 'Tendency to Spend'-TTSM, and the 'Post Purchase Guilt'PPG) by applying exploratory and confirmatory factor analysis models. We calculated the following statistics for latent variables: alpha (Cronbach 1951) and composite reliability (Jöreskog 1971; Werts et al. 1978). We also calculated the item-to-total correlations and descriptive statistics of all three latent variables and the items that were related to these factors. Thus, all analyses relied on established procedures of scale development and guidelines for testing the quality of measurements and scale assessments (see Nunnally 1978; Kline 1986). 


\subsubsection{Step 1: translation and content refinement of the P-CBS}

When translating the CBS (d'Astous et al. 1990), we followed Brislin's (1986) strategy of 'forward-backward translation' of items. As such, the original version of the compulsive buying scale (CBS; d'Astous et al. 1990) was first translated into Polish by two bilingual persons. Subsequently, another bilingual person translated the scale back into English. All translators worked independently and did not communicate about the translation.

We also asked linguistic experts to compare the retranslated version with the original one. This was done to evaluate the linguistic and cultural relevance of the translated scale. Next, we requested two experts from psychology and sociology to check the translated version for ambiguous words and to assess the ease of comprehension of the scale. Additionally, these experts were asked to confirm the face validity of the items of the (P-CBS). This enabled us to scrutinize the first version of the P-CBS on whether its wording, or other linguistic aspects of the items as well as psychological and sociological ambiguities were misleading.

All experts agreed that all items of the P-CBS fulfilled the criteria of ease of comprehension and clarity and its potential of being administered among young Polish students. Experts only criticized the item "There are times when I have a strong urge to buy clothing, tapes, jewelries, etc." As they claimed, this item was appropriate for measuring compulsive buying in American, or more general, in Western populations, but not in Poland. The argument was that the word'tapes' and 'jewelries' presented in the item might be confusing for young Polish students. The word 'tapes' was problematic as it referred to an outdated consumer product, given that tapes were used mostly in the 1970s and 1980s. On the other hand, the word 'jewelries' refers to very luxurious products in the Polish language. These consumer products are typically bought by adults for special occasions (e.g., weddings), but not by students. For this reason, we replaced the words "tapes" and 'jewelries' with the words 'food' (instead of 'tape') and 'clothing' (instead of 'jewelries').

For an additional analysis of the content and face validity (see Nevo 1985), we conducted 21 in-depth interviews with Polish students who did not take part in the main study. The interviewees were selected because they self-reported problems with controlling their over-spending habits. Like participants of our main study, interviewees attended professional schools, high schools, or universities. We interviewed seven students per school type (e.g., high school). The aim of these interviews was to ensure the ease of comprehension of the items among young Polish students who were prone to compulsive buying. Interviewees did not report inconsistencies between items that defined the three latent variables (RA, TTSM, and PPG) of the P-CBS. We concluded that the final version of the P-CBS was ready to be administered in a sample of young Polish citizens. For detailed reports on the effects of the translation and revision of the P-CBS, see "Appendix 1".

\subsubsection{Step 2: the psychometrics of the P-CBS}

First, we explored the dimensionality of the P-CBS and then analyzed its internal consistency and validity. The structure of the P-CBS was analyzed with an exploratory factor analysis (EFA). Computing the EFA, we used the maximum likelihood method to extract factors. When we rotated the factors, we applied the Promax technique in order to attain an oblique solution. This solution allowed three of the predicted dimensions of the P-CBS (RA, TTSM, PPG) to be correlated with each other. We followed Cattell (1952) who 
argued that researchers rarely expect that factors, which measure similar constructs, will not be correlated.

The factorial structure of the P-CBS was next tested with a Confirmatory Factor Analysis (CFA). The CFA allowed us to examine the level of convergency of the extracted factors and their discriminant validity. The CFA also enabled us to explore the degree of fit of the empirical data with the postulated model and compared it with the previous structure of the P-CBS explored in the EFA. Furthermore, we conducted multiple confirmatory factor analyses (MCFA) to compare this model across the compulsive and non-compulsive young buyers. Note that for both the CFA and the MCFA analyses, the maximum likelihood estimation was applied, along with respective diagnostics such as the $\chi^{2}$ measure, comparative fit indices (CFI and TLI), the root mean square error of approximation (RMSEA), and the standardized root-mean-square residual (SRMR). Kline (2011) recommended that multiple indices should be used to provide comprehensive information for the fit of the tested model with the empirical data. Additionally, $\mathrm{Hu}$ and Bentler (1999) argued that a satisfactory degree of model fit usually requires the CFI and TLI to be larger than 0.90, the RMSEA index to be lower than 0.05 , and the SRMR index to be lower than 0.08 .

In addition to EFA analysis, we tested the Common Method Bias (CMB) by applying the procedure based on the Harman's single factor score, according to which all items (measuring respective latent variables - theoretical constructs under study) were loaded into one common factor. This procedure states that if the total variance for a single factor is less than 50\%, than it explains that CMB does not affect the data (Podsakoff et al. 2003; Podsakoff et al. 2012).

After running the EFA/CFA and CMB analyses, we computed Cronbach's alphas for each of the extracted factors and the composite reliability (see Werts et al. 1978). The reason we used two different coefficients to measure the reliability of the P-CBS can be explained as follows (see Cho 2016). First, the calculation of Cronbach's alpha requires measurement models to be tau-equivalent and all factor loadings to be equal, which is rarely the case in practice. This coefficient also underestimates the reliability of the theoretical construct (Wieland et al. 2017). Second, most of the measurement models are not tau- equivalent, but congeneric (Bagozzi and Yi 1988). For this reason, we computed an additional coefficient that indicated composite reliability. This coefficient explored the postulated existence of different factor loadings and their uniqueness, and in contrast to Cronbach's alpha, could be interpreted as an indicator of the reliable correlation of the items with the measurement model, given the assumption of the underlying latent variables, measured both by the items' factor loadings and their errors.

After exploring the reliability of the factors, we tested yet the strength of factor correlations. For this purpose, we computed the corrected item-total correlation coefficients for each set of items loading on designated factor. With these coefficients, we could explore the individual items and their consistency with the postulated factors (see Carpenter et al. 2016). Additionally, it provided us with an indication of the validity of the items and the factors under evaluation.

Furthermore, in order to test the validity of the P-CBS, we tested its connection to other theoretical variables that were supposed to be related to compulsive buying. For instance, we computed an index based on the CS (Faber and O'Guinn 1992) and checked if it correlated with the P-CBS in order to test its convergent validity. Next, we linked participants' P-CBS scores to the items that measured their self-reported buying behaviour and the amount of money they spent in a month. In particular, we tested the links between the P-CBS and the following items: the number of shopping visits that ended in a purchase within the past month; the number of hours spent in a shopping center while visiting this 
center within the past month; the total amount of money (e.g., pocket money, part-time job, scholarship, etc.) students had at their disposal in the past month; the total amount of money at students' own disposal that students spent for consumer products (e.g., "How much of the money that you had at your own disposal did you spend on product purchases in the past month?").

\section{Results}

\subsection{Exploratory (EFA) data analysis and test of CMB within the P-CBS}

In this section, we present empirical results associated with the EFA analysis first. In the EFA, we mainly tested whether the translated and modified scale (i.e., the P-CBS) reflected the same or at least an approximate configuration of factors and factor loadings as the original CBS by d'Astous et al. (1990). We observed that the KMO index (i.e., the Kaiser-Meyer-Olkin measure of sampling adequacy; see Hair et al. 2010) indicated that the selected items adequately represented all hypothesized factors in both compulsive and noncompulsive buyers (see Table 2). For instance, the KMO index had a score of 0.749 for the entire sample, a score of 0.792 for compulsive buyers, and a score of 0.691 in non-compulsive buyers. This indicated that the information provided by the input data on the proposed configuration/structure of factors was sufficient (Hair et al. 2010), although the KMO index was much more significant in compulsive buyers than in non-compulsive buyers. Also note that the EFA model was explained by $79 \%$ of the total variance in the answers within compulsive buyers and only by $65 \%$ of the total variance within non-compulsive buyers.

As far as the sizes of factor loadings are concerned, the EFA revealed factor loadings that mostly exceeded 0.50 for the entire sample. However, when we performed the same analysis (with the three factors: RA, TTSM, PPG) separately for compulsive and noncompulsive buyers, we observed that factor loadings were, on average, higher in compulsive buyers than in non-compulsive buyers (Table 2). Note that factor loadings were still satisfying in non-compulsive buyers. In this sense, the EFA computed separately for both groups of buyers provided the expected structure of the P-CBS, but clearly indicated a greater adequacy for compulsive buyers than for non-compulsive buyers.

The results of the factor correlations (RA, TTSM, PPG-see Table 2) confirmed that the factors were related to each other, although these associations varied between the two groups of buyers. For instance, in compulsive buyers, the correlation coefficient between the factors 'RA' and 'TTSM' was observed at the level of 0.680 , while in non-compulsive buyers, the correlation between the same factors was at 0.516 - proving they are statistically different $(z=1.653, p=0.049)$. However, in cases of other correlations, e.g., between the factors 'RA' and 'PPG', there was not any observed difference. The correlation in compulsive buyers was 0.339 , while in non-compulsive buyers, it was at the level of 0.259 $(z=0.563, p=0.287)$. Overall, non-compulsive buyers delivered lower correlations as compared to compulsive buyers. Considering yet the squared correlations in the factors' matrix, it was found that they were all of moderate size, confirming the discriminant validity of the factors observed in the P-CBS data. The discriminant validity of the P-CBS could therefore be used for measuring three distinct but interrelated aspects of compulsive buying.

Finally, when we conducted test of the Common Method Bias (CMB) pertaining to P-CBS structure, we applied the Harman's single factor test, proving that proposed scale items are bias free. 
Table 2 Information about factor loadings of items, factor correlations derived from EFA analysis

\begin{tabular}{|c|c|c|c|c|}
\hline \multirow[t]{2}{*}{ Symbol } & \multirow[t]{2}{*}{ Item code } & \multicolumn{3}{|c|}{ Item factor loading per respective factors } \\
\hline & & Reactive aspect (RA) & $\begin{array}{l}\text { Tendency to spend money } \\
\text { (TTSM) }\end{array}$ & Post purchase guilt'(PPG) \\
\hline \multirow[t]{12}{*}{ P-CBS } & $\mathrm{P}-\mathrm{CBS} 3$ & $.862^{\mathrm{A}} / .977^{\mathrm{B}} / .818^{\mathrm{C}}$ & & \\
\hline & P-CBS4 & $.844^{\mathrm{A}} / .893^{\mathrm{B}} / .573^{\mathrm{C}}$ & & \\
\hline & P-CBS5 & $.676^{\mathrm{A}} / .620^{\mathrm{B}} / .458^{\mathrm{C}}$ & & \\
\hline & P-CBS8 & $.852^{\mathrm{A}} / .816^{\mathrm{B}} / .601^{\mathrm{C}}$ & & \\
\hline & P-CBS1 & & $.712^{\mathrm{A}} / .792^{\mathrm{B}} / .587^{\mathrm{C}}$ & \\
\hline & P-CBS2 & & $.581^{\mathrm{A}} / .651^{\mathrm{B}} / .588^{\mathrm{C}}$ & \\
\hline & P-CBS9 & & $.674^{\mathrm{A}} / .711^{\mathrm{B}} / .591^{\mathrm{C}}$ & \\
\hline & P-CBS10 & & $.530^{\mathrm{A}} / .641^{\mathrm{B}} / .537^{\mathrm{C}}$ & \\
\hline & P-CBS11 & & $.592^{\mathrm{A}} / .658^{\mathrm{B}} / .499^{\mathrm{C}}$ & \\
\hline & P-CBS7 & & & $.590^{\mathrm{A}} / .672^{\mathrm{B}} / .409^{\mathrm{C}}$ \\
\hline & P-CBS6 & & & $.675^{\mathrm{A}} / .694^{\mathrm{B}} / .510^{\mathrm{C}}$ \\
\hline & Factors & & & \\
\hline \multirow{3}{*}{$\begin{array}{l}\text { Factor cor- } \\
\text { relation } \\
\text { matrix }\end{array}$} & 1 & 1.000 & & \\
\hline & 2 & $\begin{array}{l}.617^{\mathrm{A}} / .680^{\mathrm{B}} / .516^{\mathrm{C}} \\
(.380)^{\mathrm{A}}(.462)^{\mathrm{B}} /(.266)^{\mathrm{C}}\end{array}$ & 1.000 & \\
\hline & 3 & $\begin{array}{l}.218^{\mathrm{A}} / .339^{\mathrm{B}} / .259^{\mathrm{C}} \\
(.047)^{\mathrm{A}} /(.115)^{\mathrm{B}} /(.067)^{\mathrm{C}}\end{array}$ & $\begin{array}{l}.435^{\mathrm{A}} / .434^{\mathrm{B}} / .310^{\mathrm{C}} \\
(.189)^{\mathrm{A}} /(.188)^{\mathrm{B}} /(.096)^{\mathrm{C}}\end{array}$ & 1.000 \\
\hline
\end{tabular}

The following capital letters denote values obtained for respective groups of buyers: A-Total sample; BCompulsive buyers; C-Non-compulsive buyers

Kaiser-Meyer-Olkin Measure of Sampling Adequacy was calculated for the entire sample $\mathrm{KMO}^{\mathrm{A}}=.749$ and both groups of buyers separately: $\mathrm{KMO}^{\mathrm{B}}=.792 ; \mathrm{KMO}^{\mathrm{C}}=.691$

Extraction method: Maximum likelihood and Promax rotation with Kaiser Normalization at $72 \%$ of variance explained in the total sample A; 79\% variance explained in non-compulsive buyers; and a $65 \%$ level of variance in compulsive buyers

In factor correlation matrix, in the parentheses squared correlations between factors are presented

\subsection{Confirmatory (CFA) analysis of the P-CBS}

The structure of the P-CBS, built on three factors, was statistically tested by a Confirmatory Factor Analysis (CFA). As displayed in Table 3, the CFA model provided a reasonable goodness-of-fit for the entire sample $\left(\chi^{2}=113.549, \mathrm{df}=41, p=0.00 ; \mathrm{CFI}=0.967\right.$; $\mathrm{TLI}=0.954$; $\mathrm{SRMR}=0.039$; RMSEA $=0.059)$ and for compulsive buyers $\left(\chi^{2}=55.549\right.$, $\mathrm{df}=41, p=0.055 ; \mathrm{CFI}=0.964 ; \mathrm{TLI}=0.952 ; \mathrm{SRMR}=0.062 ; \mathrm{RMSEA}=0.056)$. In compulsive buyers, the CFI and the TLI indices were larger than 0.95, and the RMSEA index was slightly above the standard cut-off value of 0.05 , whereas the SRMR index was below 0.08 (see Hu and Bentler 1999). In contrast, for non-compulsive buyers, the fit of the model was only moderate $\left(\chi^{2}=104.312, \mathrm{df}=41, p=0.00 ; \mathrm{CFI}=0.931 ; \mathrm{TLI}=0.919 ; \mathrm{SRMR}=0.128\right.$; RMSEA $=0.091)$.

We also tested the CFA model in accordance with Byrne (2013), first regarding the feasibility of the parameter estimates, and second on the statistical significance of the parameter estimates (Table 3). Note in this case that a possible lack of the feasibility of the parameter estimates might be indicated if an estimate's algebraic sign would be opposite to what could have been expected (e.g., it would be positive in cases where one could reasonably 


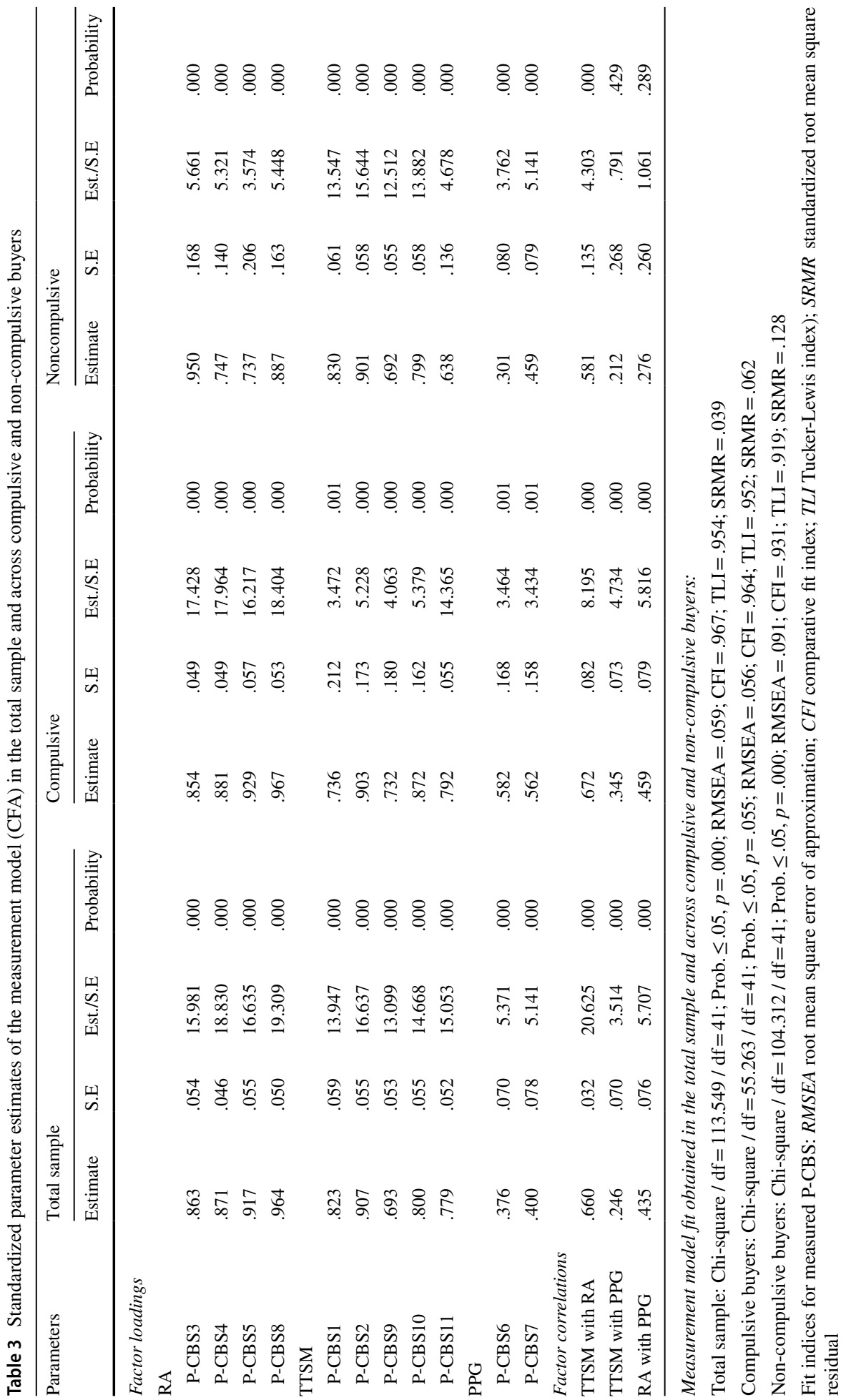


Table 4 Testing the measurement model (MGCFA) across compulsive and non-compulsive buyers

\begin{tabular}{lllll}
\hline Types of indices & Configural invariance & $\begin{array}{l}\text { Factor load- } \\
\text { ings invari- } \\
\text { ance } \\
\text { Constrained equal across groups } \\
\text { imposed }\end{array}$ & $\begin{array}{l}\text { Factor loadings and } \\
\text { item intercepts invari- } \\
\text { ance }\end{array}$ & $\begin{array}{l}\text { Factor loadings, item } \\
\text { intercepts and structural } \\
\text { means invariance }\end{array}$ \\
\hline Chi-square & 122.948 & 152.123 & 171.256 & 193.198 \\
Df & $\mathrm{df}=93$ & $\mathrm{df}=101$ & $\mathrm{df}=104$ & $\mathrm{df}=107$ \\
Prob. $\leq 0.05$ & $p=.000$ & $p=.000$ & $p=.000$ & $p=.000$ \\
RMSEA & .057 & .088 & .089 & .094 \\
CFI & .945 & .910 & .907 & .898 \\
TLI & .932 & .909 & .905 & .892 \\
\hline
\end{tabular}

expect a negative sign) or in cases where its size would be outside the admissible range. Now, as our estimates (Table 3) showed, for the entire sample and for compulsive and noncompulsive buyers alone, that these problems did not occur in the tested model. There were no abnormalities in the total sample, nor in compulsive or non-compulsive buyers. But we found that for the model parameters, in non-compulsive buyers, two of three correlations between factors (the correlation between TTSM and PPG, and the correlation between RA and PPG) were not significant. In contrast, all correlations between factors were significant in compulsive buyers.

\subsection{Multiple-group confirmatory factor analysis: compulsive and non-compulsive buyers}

As we found some differences between compulsive and non-compulsive buyers in the CFA measurement model, we decided to compare this model across both groups (compulsive, and non-compulsive buyers) in order to determine whether all observed differences can be proved statistically. We performed multiple group analyses (MCFA) in order to explain the variation of responses on the items within all three extracted factors RA, TTSM, and PPG. We assumed configural, metric, and scalar invariances of these factors (see Cheung and Rensvold 1999). We claimed that if the original model would indicate a reasonable fit, it could be used as a baseline for comparisons with all other models that were subsequently found in the hierarchy. In that sense, exploring the invariance within the P-CBS relied on a series of tests that checked dispersions in compulsive and non-compulsive buyers.

According to the test of configural invariance, the following findings emerged (Table 4). First, the chi-square measure (without constraints imposed) ended in a score of 122.95, with $\mathrm{df}=93$ and $p=0.034$, while the RMSEA index showed a decent fit of the model (0.057). Also, the CFI $(=0.945)$ indicated a good fit of the model (Hu and Bentler 1999). The same was true for the TLI index (0.932), which proved that the general configural model fit the empirical data quite well. As a result, we assumed that the postulated factors (RA, TTSM, PPG) were appropriately represented by the CFA model in the total sample.

However, when we tested the metric invariance by considering the equality of factor loadings across compulsive and non-compulsive buyers, and while the intercepts could differ between these two groups of buyers, the results were not as satisfying (see Table 4). For instance, there was an increase in the values of the overall fit of the model compared to the 
results of configural testing $\left(\Delta \chi_{11}^{2}=57.546\right.$ at $\left.p=0.000\right)$. In other words, by contrasting the configural invariance with the metric variance, we noticed that the $\Delta \chi^{2}$ measure obtained a non-statistical fit $\left(\Delta \chi_{8}^{2}=29.174\right.$ at $\left.p=0.000\right)$. The same was found for the $\Delta$ CFI index (0.035) and the $\Delta$ TLI index (0.023), which showed a greater difference between the first and the second analytical option. Note that in the evaluation process of the goodness-of-fit indices associated with testing measurement invariances, differences above 0.01 are usually considered as problematic both for the interpretation and the acceptance of measurement models (Cheung and Rensvold 2002).

Consequently, we inferred that the sizes of some factor loadings were not equal in both groups of consumers. It turned out that compulsive buyers obtained higher levels of factor loadings than non-compulsive buyers. Thus, we concluded that young compulsive consumers attributed a slightly different meaning to the behavior they rated on different scales and that were indicative of compulsive buying. Indeed, compulsive buyers differed in their interpretation of this behavior, and therefore we reject the assumption of metric invariance of the MCFA model for both groups of buyers. Also note that continuing the process of testing the scalar invariance of the P-CBS would fail in providing a reasonable model fit. The analyses (based on intercepts invariance) indicated that the MCFA model has become even worse as compared to the configural and metric invariance of the model. This supported our decision to reject the assumption of the equality of the items (i.e., the invariance of the intercepts). For the same reason, we did not analyze the factor means, variances, or residual variances.

Lastly, due to our findings reported above, we claimed that both groups of buyers had different ideas about the nature of compulsive buying behavior. They showed more differences between their interpretation of the items asking for compulsive buying tendencies than consensus. We postulated that the CFA model has a statistically better fit in compulsive buyers $\left(\chi^{2}=55.263, \mathrm{df}=41, p=0.055\right.$; $\mathrm{CFI}=0.964$; $\mathrm{TLI}=0.952$; $\mathrm{SRMR}=0.062$; RMSEA $=0.056)$ than in non-compulsive buyers $\left(\chi^{2}=104.312, \mathrm{df}=41, p=0.000\right.$; $\mathrm{CFI}=0.931$; $\mathrm{TLI}=0.919$; $\mathrm{SRMR}=0.128$; RMSEA $=0.091$ ). Our findings suggested that the P-CBS provided a better fit in compulsive than in non-compulsive buyers on the structure of the model/scale. These findings confirmed our idea to distinguish compulsive and non-compulsive buyers after testing the model fit of the P-CBS on the entire sample. The $\mathrm{P}-\mathrm{CBS}$ seems to be well-suited to asses compulsive buying behavior in general, but even more so in a population that is prone to compulsive buying. For non-compulsive buyers, the P-CBS turned out to be less suited as a measurement of compulsive buying indicated by several statistical properties.

\subsection{The psychometric quality of the items of the P-CBS regarding the factors TTSM, $R A$, and PPG}

For a more thorough testing of the adequacy of the factors RA, TTSM, and PPG as dimensions of the P-CBS, we computed correlations between their items (Table 5). According to Wieland et al. (2017), simple correlations allow the assessment of the quality of items as input data of factor analyses. Correlations indicate if two items cover the same domain or might be associated with different constructs.

Regarding the factor RA, among the compulsive buyers, we observed the highest correlation between the items P-CBS4 and P-CBS8 ( $r=0.625$, see Table 5) within the same factor, while the lowest correlation between P-CBS5 and P-CBS3 $(r=0.521)$. Also, in the group of non-compulsive buyers, the lowest correlation $(r=0.324)$ was observed between 
Table 5 Information on the quality of particular items in connection with designated factors

\begin{tabular}{|c|c|c|c|c|c|c|c|c|c|}
\hline \multirow[t]{2}{*}{ Symbol } & \multirow[t]{2}{*}{ Item } & \multicolumn{5}{|c|}{ Correlations between items } & \multirow[t]{2}{*}{ CITC } & \multirow{2}{*}{$\begin{array}{l}\text { Alpha reli- } \\
\text { ability }\end{array}$} & \multirow{2}{*}{$\begin{array}{l}\text { Com- } \\
\text { posite } \\
\text { reli- } \\
\text { ability }\end{array}$} \\
\hline & & P-CBS3 & P-CBS4 & P-CBS5 & P-CBS8 & & & & \\
\hline \multirow[t]{4}{*}{ RA } & P-CBS3 & 1.000 & & & & & $\begin{array}{l}.687^{\mathrm{A}} \\
.697^{\mathrm{B}} \\
.677^{\mathrm{C}}\end{array}$ & $\begin{array}{l}.850^{\mathrm{A}} \\
.843^{\mathrm{B}} \\
.763^{\mathrm{C}}\end{array}$ & $\begin{array}{l}.861^{\mathrm{A}} \\
.858^{\mathrm{B}} \\
.826^{\mathrm{C}}\end{array}$ \\
\hline & P-CBS4 & $\begin{array}{l}.621^{\mathrm{A}} \\
.617^{\mathrm{B}} \\
.661^{\mathrm{C}}\end{array}$ & 1.000 & & & & $\begin{array}{l}.711^{\mathrm{A}} \\
.722^{\mathrm{B}} \\
.707^{\mathrm{C}}\end{array}$ & & \\
\hline & P-CBS5 & $\begin{array}{l}.505^{\mathrm{A}} \\
.521^{\mathrm{B}} \\
.324^{\mathrm{C}}\end{array}$ & $\begin{array}{l}.559^{\mathrm{A}} \\
.561^{\mathrm{B}} \\
.545^{\mathrm{C}}\end{array}$ & 1.000 & & & $\begin{array}{l}.639^{\mathrm{A}} \\
.653^{\mathrm{B}} \\
.481^{\mathrm{C}}\end{array}$ & & \\
\hline & P-CBS8 & $\begin{array}{l}.616^{\mathrm{A}} \\
.618^{\mathrm{B}} \\
.584^{\mathrm{C}}\end{array}$ & $\begin{array}{l}.616^{\mathrm{A}} \\
.625^{\mathrm{B}} \\
.508^{\mathrm{C}}\end{array}$ & $\begin{array}{l}.572^{\mathrm{A}} \\
.578^{\mathrm{B}} \\
.509^{\mathrm{C}}\end{array}$ & 1.000 & & $\begin{array}{l}.722^{\mathrm{A}} \\
.721^{\mathrm{B}} \\
.718^{\mathrm{C}}\end{array}$ & & \\
\hline Symbol & Item & P-CBS1 & P-CBS2 & P-CBS9 & P-CBS10 & P-CBS11 & & & \\
\hline \multirow[t]{5}{*}{ TTSM } & P-CBS1 & 1.000 & & & & & $\begin{array}{l}.584^{\mathrm{A}} \\
.589^{\mathrm{B}} \\
.541^{\mathrm{C}}\end{array}$ & $\begin{array}{l}.743^{\mathrm{A}} \\
.789^{\mathrm{B}} \\
.660^{\mathrm{C}}\end{array}$ & $\begin{array}{l}.761^{\mathrm{A}} \\
.795^{\mathrm{B}} \\
.690^{\mathrm{C}}\end{array}$ \\
\hline & P-CBS2 & $\begin{array}{l}.501^{\mathrm{A}} \\
.606^{\mathrm{B}} \\
.455^{\mathrm{C}}\end{array}$ & 1.000 & & & & $\begin{array}{l}.598^{\mathrm{A}} \\
.606^{\mathrm{B}} \\
.597^{\mathrm{C}}\end{array}$ & & \\
\hline & P-CBS9 & $\begin{array}{l}.434^{\mathrm{A}} \\
.423^{\mathrm{B}} \\
.526^{\mathrm{C}}\end{array}$ & $\begin{array}{l}.446^{\mathrm{A}} \\
.450^{\mathrm{B}} \\
.410^{\mathrm{C}}\end{array}$ & 1.000 & & & $\begin{array}{l}.528^{\mathrm{A}} \\
.631^{\mathrm{B}} \\
.518^{\mathrm{C}}\end{array}$ & & \\
\hline & P-CBS10 & $\begin{array}{l}.446^{\mathrm{A}} \\
.454^{\mathrm{B}} \\
.366^{\mathrm{C}}\end{array}$ & $\begin{array}{l}.458^{\mathrm{A}} \\
.444^{\mathrm{B}} \\
.622^{\mathrm{C}}\end{array}$ & $\begin{array}{l}.392^{\mathrm{A}} \\
.374^{\mathrm{B}} \\
.591^{\mathrm{C}}\end{array}$ & 1.000 & & $\begin{array}{l}.541^{\mathrm{A}} \\
.645^{\mathrm{B}} \\
.532^{\mathrm{C}}\end{array}$ & & \\
\hline & P-CBS11 & $\begin{array}{l}.514^{\mathrm{A}} \\
.505^{\mathrm{B}} \\
.605^{\mathrm{C}}\end{array}$ & $\begin{array}{l}.489^{\mathrm{A}} \\
.490^{\mathrm{B}} \\
.458^{\mathrm{C}}\end{array}$ & $\begin{array}{l}.459^{\mathrm{A}} \\
.479^{\mathrm{B}} \\
.303^{\mathrm{C}}\end{array}$ & $\begin{array}{l}.509^{\mathrm{A}} \\
.499^{\mathrm{B}} \\
.629^{\mathrm{C}}\end{array}$ & 1.000 & $\begin{array}{l}.595^{\mathrm{A}} \\
.594^{\mathrm{B}} \\
.584^{\mathrm{C}}\end{array}$ & & \\
\hline Symbol & Item & P-CBS6 & P-CBS7 & & & & & & \\
\hline \multirow[t]{2}{*}{ PPG } & P-CBS6 & 1.000 & & & & & $\begin{array}{l}.537^{\mathrm{A}} \\
.567^{\mathrm{B}} \\
.378^{\mathrm{C}}\end{array}$ & $\begin{array}{l}.753^{\mathrm{A}} \\
.736^{\mathrm{B}} \\
.684^{\mathrm{C}}\end{array}$ & $\begin{array}{l}.764^{\mathrm{A}} \\
.741^{\mathrm{B}} \\
.696^{\mathrm{C}}\end{array}$ \\
\hline & P-CBS7 & $\begin{array}{l}.662^{\mathrm{A}} \\
.687^{\mathrm{B}} \\
.598^{\mathrm{C}}\end{array}$ & 1.000 & & & & $\begin{array}{l}.656^{\mathrm{A}} \\
.767^{\mathrm{B}} \\
.598^{\mathrm{C}}\end{array}$ & & \\
\hline
\end{tabular}

CITC corrected item-total correlation for particular items. Groups denoted as in Table 2

the items P-CBS5 and P-CBS3, while the highest $(r=0.661)$ was observed between the items P-CBS3 and CBS4.

In case of factor TTSM, the lowest correlation $(r=0.374)$ in the group of compulsive buyers was observed between the items P-CBS9 and P-CBS10, while the highest correlation of items within this factor was found between the items P-CBS1 and P-CBS2 $(r=0.606)$. On the other hand, in non-compulsive buyers, the lowest correlation was observed between the items P-CBS9 and P-CBS11 ( $\mathrm{r}=0.303)$ while the highest emerged between the items P-CBS10 and P-CBS11 $(r=0.629)$. 
Finally, in compulsive buyers, the correlation between the items P-CBS6 and P-CBS7 of the third factor PPG was $r=0.687$, while in non-compulsive buyers this correlation between the same items was observed at the level of 0.598. In general, we can argue that all the corrected item-total correlations between the items reached an acceptable level of scores (see Clark and Watson 1995).

\subsection{The reliability and internal consistency of the extracted factors}

Next, we examined the reliability of each factor and the item-total correlations between the items and the overall score of the P-CBS. Regarding the reliability, we followed Nunnally (1978) who claimed that a Cronbach's alpha above 0.70 indicates sufficiently high reliability of a construct, although Cronbach's alphas between 0.80 and 0.90 are definitively better (see Wieland et al. 2017). According to Werts et al. (1978), the composite reliability index should be greater than 0.70 in order to demonstrate a sufficient reliability of a scale.

Following these suggestions and guidelines, we concluded that the reliability coefficients of all three factors observed in the data of the present study matched the requirements of reliable scales (Table 5). There were some exceptions, though. For instance, the factor 'Tendency to Spend Money' only showed a Cronbach's alpha of 0.660 in non-compulsive buyers. Likewise, the factor 'Post-Purchase Guilt' had a Cronbach's alpha of 0.684 in non-compulsive buyers, and the composite reliability did not exceed 0.70 for the following factors: TTSM (0.690) and PPG (0.696).

It is also worth noting that the alpha coefficients showed generally lower values than the composite coefficients in all analyses. These differences relied on measurement errors. Cronbach's alpha only yields unbiased estimates of reliability if items of a factor are equal and have approximately equal covariances as well as equal prospective error variances (see Shevlin et al. 2000). When items have equal scores but differ in their error variances, we obtain tau-equivalence. Due to these findings, the P-CBS and its factors were a congeneric solution. Items of the factors RA, TTSM, and PPG showed that their factor loadings had slightly different values within the factors both when being analyzed in the total sample and when computed separately for compulsive and non-compulsive buyers (see Table 3). We claim that the composite reliability coefficient delivered more information about the reliability of the P-CBS and yielded more precise data about the three hypothesized factors as Cronbach's alpha.

\subsection{Examination of the P-CBS validity}

Finally, we tested the overall validity of the P-CBS as a theoretical construct created to measure compulsive buying in Poland. For this purpose, we included the CS (Faber and O'Guinn 1992) and four items assumed to measure 'self-reported buying behavior and the amount of money spent per month' (see Table 6) in our analyses. In order to explore the convergent or nomological validity of the P-CBS, we first formed an index (P-CSI) by summing up the scores of the seven items of the CS (Faber and O'Guinn 1992). Note that we called this index "P-CSI" to emphasize that it was the CS adapted for being administered in Polish samples (i.e., translated into Polish).

Next, we computed the indices for each of the three factors (RAI, TTSMI, PPGI) of the P-CBS separately. All indices were computed by summarizing the scores of the items within the respective factor. Next, we computed the general Polish-Compulsive Buying Index (P-CBSI) by summarizing all the scores of the P-CBS scale, which comprised all 


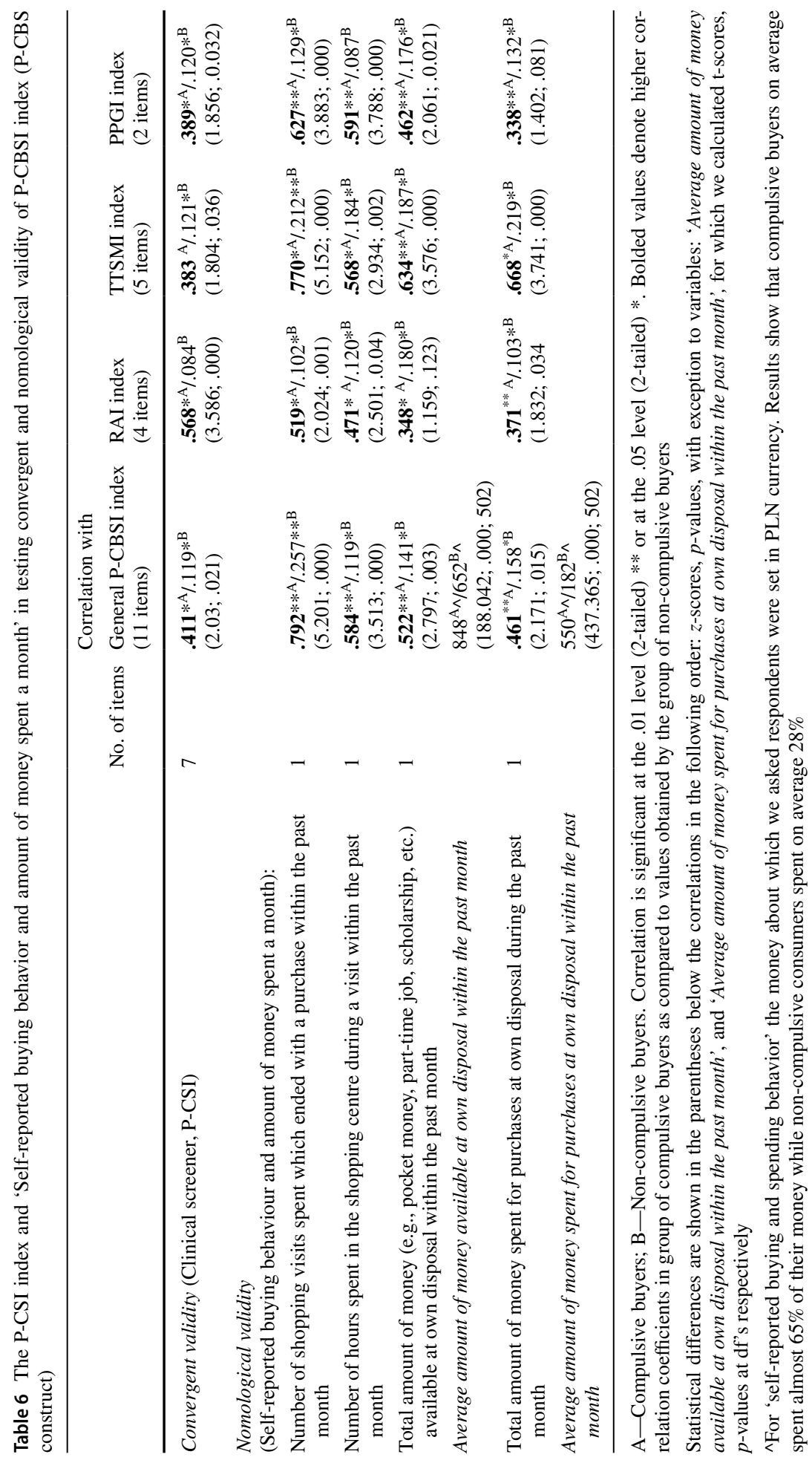


three sets of items from all three factors (RA, TTSM, PPG). Finally, we computed simple correlations of the P-CBSI, RAI, TTSMI, and PPGI indices with the P-CSI and the item 'self-reported buying behavior and the amount of money spent per month'. In sum, the general index of compulsive buying (P-CBSI) was based on participants' scores of 11 items; while the other three indices were obtained by summarizing the scores of four items (RAI), five items (TTSMI), and the scores of two items (PPGI). Finally, all indices were calculated separately for compulsive and non-compulsive buyers. The results are presented in the next sections.

\subsubsection{The convergent validity of the P-CBSI index}

In this section, we present the results of the correlation of the P-CBSI with the P-CSI. Table 6 presents the results for each group of buyers separately. The correlation between the P-CBSI and the P-CSI was positive and significantly higher in compulsive buyers $(r=0.411)$ as compared to non-compulsive buyers $(r=0.119)$, at $z=2.031$ and $p=0.021$. Then, correlations between the P-CSI and the the RAI $(r=0.568 ; z=3.586, p=0.000)$, TTSMI $(r=0.383 ; z=1.804, p=0.036)$, and the PPGI $(r=0.389 ; z=1.856, p=0.032)$ were calculated. The higher the correlations between all of these indices were, the better the construct's convergence in a group of buyers was. In other words, compulsive buyers self-reported higher levels of compulsive buying behavior on both the P-CBS and the CS compared to non-compulsive buyers (see also Faber and O'Guinn 1992). This finding confirmed that the P-CBS was a valid measure of compulsive buying.

The CS (Faber and O'Guinn 1992) and the P-CBS included items that clearly referred to the loss of control over buying and emphasized the role of emotions in buying (i.e., the emotional instability experienced when buying something). In addition, both constructs referred to consumers' irrationality by asking both for uncontrollable buying behavior and the irresistible desire to buy something (Grougiou, Kapoutsis and Moschis 2015). This becomes a pathological habit leading to negative consequences for buyers (Flight, Rountree, and Beatty 2012). Hence, our analyses provided evidence that in the population of young consumers in Poland, compulsive buying is strongly related to irrational and destructive (i.e., excessive) types of addiction (see Yuengert 1997; Tomer 2001).

\subsubsection{The nomological validity of the P-CBSI}

Finally, in order to evaluate the nomological validity of the Polish compulsive-buying index (P-CBSI), we correlated this index with the items 'self-reported buying behavior and amount of money spent per month'. Specifically, we asked participants about the number of shopping tours that ended in a purchase in the past month, and the number of hours spent in a shopping mall during a visit in the past month. Next, we asked the participants to reveal the total amount of money (e.g., pocket money, money earned in a part-time job, scholarship, etc.) they had at their own disposal for purchases in the past month and the total amount of money spent on purchases to satisfy their own needs in the past month. In other words, we wanted to know how much consumers spent on clothing, gadgets, media, and so on per month. We computed the average for the money spent for these products in a month.

Likewise, we asked for the amount of money our participants could spend at their own disposal (Table 6). It turned out that the correlation between the compulsive consumers' general index P-CBSI and their purchase was high $(r=0.522)$, while in the case of 
non-compulsive consumers, this correlation was weaker $(r=0.141)$, thus proving statistical difference between these groups at $z=2.797, p=0.003$. In other words, non-compulsive buyers expressed lower needs in spending money and lower desires to buy many kinds of 'stuff' as well.

The results also showed that compulsive buyers spent on average 550 PLN (zloty) per month, while non-compulsive consumers spent only 182 PLN on average per month. The statistical difference was $t=437.365, p=0.000, \mathrm{df}=502$. Comparing the average amount of money at their own disposal (848 PLN in compulsive buyers and 652 in non-compulsive buyers, $t=188.042, p=0.000, \mathrm{df}=502$ ), we noticed that compulsive consumers spent $65 \%$ of this money in a month on average, while non-compulsive consumers spent only $28 \%$ of that money.

We also noticed that both the money at their own disposal and the money participants spent in a month correlated positively with all three factors (RAI, TTSMI, and PPGI) observed in the entire sample, but especially so within compulsive buyers (see Table 6). It also turned out that consumers who were more inclined towards compulsive buying behavior (diagnosed by the CS; Faber and O'Guinn 1992) felt a greater urge to spend all their money immediately. They were unable to control their buying behavior, or at least reported having a harder time controlling their own spending behavior and keeping the money they received or earned than non-compulsive buyers.

Compulsive buyers also self-reported higher numbers of shopping visits that ended with a purchase in the past month, and more hours spent in a shopping mall in the past month than non-compulsive buyers (the correlation of the P-CBSI with the number of shopping tours that ended with a purchase in the past month was $r=0.792$ ). Also, the correlation between the P-CBSI and the TTSMI in compulsive buyers was $r=0.770$, the correlation between the P-CBSI and the RAI was $r=0.519$, and the correlation between the P-CBSI and the PPGI was $r=0.627$. In contrast, the correlation between the P-CBI and the number of shopping tours that ended with a purchase in the past month in non-compulsive buyers was $r=0.257$, and the correlation between the P-CBSI and the TTSMI was $r=0.212$, while the P-CBSI hardly correlated with the RAI $(r=0.102)$, nor did the P-CBI correlate with the PPGI $(r=0.129)$. All of these correlations between the two groups of buyers were statistically different (Table 6).

Nearly the same pattern of results appeared for the number of hours spent in a shopping center. The correlation coefficients between this variable and the P-CBSI and its subdimensions were higher on average in compulsive buyers $(\mathrm{P}-\mathrm{CBSI}=0.584$; TTSMI $=0.568$; $\mathrm{PPGI}=0.627$; RAI $=0.471$ ) as compared to non-compulsive buyers. For the latter, the correlation coefficients between hours spent in a shopping center and the P-CBSI and indexes that were based on their factors were the following: P-CBSI $=0.119$; TTSMI $=0.184$; $\mathrm{RAI}=0.120 ; \mathrm{PPGI}=0.087$. They were all significant except the last correlation.

\section{Discussion}

We tested a carefully translated and slightly modified version of the Compulsive Consumer Scale (d'Astous et al. 1990) on its reliability and validity. As a sample, we investigated young consumers in Poland. Hence, we explored compulsive buying tendencies in young people in a country that went through a remarkable socio-economic-cultural transition in the last 20 years. The strengths of the study were that we collected field data from students of high schools, professional schools, and universities in different Polish regions and that 
the sample was relatively large (more than 500 students participated). Bilingual speakers translated the scale into Polish and back into English. We also asked several experts from psychology and sociology to evaluate how appropriate the translated and modified version of the scale was for being administered in the Polish culture. Further, experts were asked how adequate the scale was for investigating young consumers. Overall, we strictly followed the process of scale development according to well-known methodological rules (Kline 1986; Nunnally 1978) by taking care of specific details at every stage of the scale construction and its modification.

Our findings suggested that the translated version of the CBS (d'Astous 1990), that we called Polish-Consumer Buying Scale (P-CBS), was highly reliable and valid in terms of identifying compulsive buyers. The P-CBS turned out to rely on the following three factors or dimensions: a reactive aspect of compulsive buying, the tendency to spend money, and post-purchase guilt. This factor structure was equal to that of the CBS (see d'Astous 1990). Due to our results, we concluded that the P-CBS can be used to identify people with compulsive buying issues in Poland. This holds especially in younger samples, but note that the P-CBS scale yielded different results on the psychometric descriptive statistics and the factor analysis in two groups of buyers, compulsive and non-compulsive buyers. Non-compulsive buyers obtained on average worse results than compulsive buyers in terms of the size and the structure of the factor loadings, the effects of model fit to the data, the reliability, and validity of the coefficients, etc. Hence, we argue that the P-CBS scale validly measures extreme tendencies of compulsive buying behavior in contrast to less extreme forms which are beyond this diagnosis.

Given all these facts, the hypotheses A1, A2a, b were largely confirmed. We claim that Polish compulsive versus non-compulsive young buyers respond differently to the three dimensions of the P-CBS. This scale, administered to compulsive buyers, indicates a high level of coherence within the structure of the measurement model and a high reliability within each of its three hypothesized factors (RA, TTSM, and PPG). Conversely, in noncompulsive buyers, the P-CBS indicated a low coherence within the structure of the measurement model and low reliability within each of its three expected factors (RA, TTSM, and PPG). Lastly, we found evidence for hypotheses A3a, b, and argue that the P-CBS scale in compulsive buyers indicated strong correlations with the 'Clinical Screener' (CS Faber and O'Guinn 1992) and variables measuring the 'Self-reported buying and spending behavior' of consumers. Whereas in non-compulsive buyers, this scale showed low correlations with the CS (Faber and O'Guinn 1992) and the constructs of 'Self-reported buying and spending behavior'.

\section{Theoretical and practical implications}

Although compulsive buying appears to be commonly accepted in well-developed countries, mostly Western cultures (Scherhorn et al. 1990, 1992; Koran et al. 2006), it is also growing rapidly in developing economies and Eastern cultures due to major socio-economic transitions (Hofstede 2001; Luthar 2006). Such a transition occurred in Poland when it alternated its socialistic economic system into capitalism and a free market economy. Therefore, we claimed that the scale that we developed and validated in our study has benefits for researchers interested in diagnosing compulsive buying.

The diagnosis of compulsive buying is not a straightforward process, but still it has to be done accurately. This diagnosis helps theorists and practitioners to understand this 
phenomenon better and to predict, for instance, its increase (see also Hassay and Smith, 1996). In this sense, our work contributed to the development of theories on compulsive buying and to consumer research in general (e.g., O'Guinn and Faber 1989; d'Astous et al. 1990; Scherhorn et al. 1990, 1992; Koran et al. 2006; Flight et al. 2012; Palan et al. 2014). This contribution it threefold. First, we diagnosed the compulsive buying in an Eastern European country, Poland. Note that this region is heavily underinvestigated in the field of consumer research in general, and specifically in the field of compulsive buying. Compared to work conducted by Tarka and Kukar-Kinney (2020), we measured compulsive buying in a sample of young people through different scale. Second, we both developed and validated the original version of the CBS scale (d'Astous et al. 1990), to fit with the Polish sociocultural conditions. Third, we did not analyze the entire sample, but diagnosed compulsive buying tendencies in two distinct groups of consumers, compulsive and non-compulsive buyers. As observed, the interpretation of the same measurement items of the P-CBS varied strongly between compulsive and non-compulsive buyers. This finding enriches the concept of compulsive buying because both groups interpret the behaviors described in the P-CBS differently. Overall, the theoretical contribution of this study is both methodological and substantive.

On the other hand, speaking of practical implications, the P-CBS scale is beneficial for practitioners in schools, e.g., teachers, and other persons responsible for supervising and planning educational programs. The data collected through this scale could be also helpful when developing preventive actions suited to stop the further proliferation of unwanted compulsive buying in this part of Europe (see also Keeley and Buehler 2016; Tarka and Kukar-Kinney 2020). In other words, high schools, professional schools, and universities in Poland should take actions to prevent extreme forms of compulsive shopping among their students. For those young people who already suffer from strong compulsive buying problems, psychological interventions and educational programs should be offered that, for instance, strengthen students' self-control. Another idea could be to enhance students' financial literacy in high school by including lessons on this topic in regular teaching subjects such as economics. For example, courses such as home economics or personal finance could include some coverage of this topic. Students could also be encouraged to respond to the P-CBS measure and evaluate their own level of compulsive buying tendencies. In sum, knowing more about compulsive buying can help to both better understand the compulsive buying phenomenon and its implications for consumers' personal lives, society, and culture. This knowledge might help to prevent a further spread of this harmful behavior across different groups in society.

\section{Limitations of research}

Although our sample is large one and its structure resembles the population of young Polish people sufficiently, given the design of our study, we believe that a highly representative sample size of young Polish consumers [calculated on the basis of 4.23 million consumers aged 17-24 years; see Central Statistical Office in Poland (2018)] at 95\% confidence level and a 2.36 margin of error, would require data collection of the approximate size of 1700 participants [e.g. as indicated in sampling report of European Social Survey (2019)]. On the other hand, the minimum but still effective sample size (obtained at $95 \%$ confidence and slightly higher margin error 4.36) would require a sample size of 505 participants, which in fact matches the sample size from this study. 
A weakness of our sample is that it does not include young Polish consumers who are unemployed or employed without attending a professional school or university.

Besides, since the present research was aimed at assessing validity and reliability of the adapted instrument, at essentially the same time, it has not investigated its temporal stability. Thus, longitudinal studies are needed to evaluate the extent of temporal stability of the scale. In particular, it would be interesting to investigate the properties of scale and adherent constructs (RA, TTS, PPG) in a test/re-test form, including further test of predictive validity assuming that respective criterion validity would be obtained sometime after performing initial measurement. By conducting this validity, one would identify the level of 'prognosis' of the scores within the approximate bounds of adapted scale and its constructs (Bechtoldt 1959).

Another critical aspect of this study is that our findings cannot be generalized to the general population of adults in Poland as the items were modified that they fit the purpose of measuring compulsive buying in young consumers only. Further, given that the scale was adapted for the Polish culture, it is quite natural that we do not know whether the same results would be observed in neighboring countries that are also part of Eastern European culture (e.g., Czech Republic, Hungary, Slovenia, Slovakia, etc.). These countries also have experienced communism over decades and came a long way from socialism to capitalism and a free market. Finally, our data were exclusively collected by self-reports through scales and questionnaires. We therefore cannot test their links to objective behavioral measurements. Future studies should take care of this problem by connecting consumers' self-reported compulsive buying behavior to behavioral measures such as actual purchase data or consumer debts.

\section{Conclusions}

We successfully adapted the compulsive buying scale (CBS; d'Astous et al. 1990) for the use in a sample of young Polish consumers. Results of this work suggested the high reliability and validity of the Polish-Compulsive Consumer Scale (P-CBS), especially in compulsive buyers, That is, in young consumers that report problems with controlling their buying behavior and their spending of money as well. The main factors of the P-CBS resembled those of the original scale structure (i.e., the CBS; d'Astous, 1990). These factors were the following: the tendency to spend money, a reactive aspect of compulsive buying, and post-purchase guilt. These factors reflected the view of young Polish consumers on their compulsive buying problems. Hence, we can claim that the P-CBS characterized the behavior of (young) compulsive buyers in Poland very well.

Funding This work was supported by National Science Centre in Poland (Grant 'Miniatura' No. 2017/27/B/ HS4/00193).

\section{Compliance with ethical standards}

Conflict of interest There is no conflict of interest.

Open Access This article is licensed under a Creative Commons Attribution 4.0 International License, which permits use, sharing, adaptation, distribution and reproduction in any medium or format, as long as you give appropriate credit to the original author(s) and the source, provide a link to the Creative Commons 
licence, and indicate if changes were made. The images or other third party material in this article are included in the article's Creative Commons licence, unless indicated otherwise in a credit line to the material. If material is not included in the article's Creative Commons licence and your intended use is not permitted by statutory regulation or exceeds the permitted use, you will need to obtain permission directly from the copyright holder. To view a copy of this licence, visit http://creativecommons.org/licenses/by/4.0/.

\section{Appendix 1}

Compulsive Buying Scale (D'Astous et al. 1990).

P-CBS scale powstrzymać i wydaję jakąś ich część lub wszystkie

Często kupuję sobie w sklepie coś, co nie było przeze mnie wcześniej zaplanowane, bo czuję, że muszę to mieć

Zakupy są dla mnie sposobem na relaks $\mathrm{i}$ zapomnienie o problemach

Czasem czuję, że coś od wewnątrz zmusza mnie do pójścia na zakupy

Niekiedy odczuwam silne pragnie zakupu czegoś (np. jakiegoś ubrania; jedzenia, itp.)

Często odczuwam poczucie winy po zakupieniu czegoś, ponieważ taki zakup później okazuje się być nieuzasadniony

Niektórych z zakupionych rzeczy nie pokazuję nikomu, ponieważ ktoś mógłby pomyśleć, że jest to głupi wydatek i zmarnowanie pieniędzy

Często odczuwam silne pragnienie, aby wybrać się na zakupy i coś sobie kupić

Często zdarzało mi się kupić niepotrzebny produkt, nawet jeśli wiedziałem, że mam mało pieniędzy

Lubię wydawać pieniądze na różne rzeczy

Kiedy tylko wchodzę do centrum handlowego, zawsze chcę wejść do sklepu i coś sobie kupić
P-CBS1 When I have money, I cannot help but spend part or the whole of it

CBS scale

P-CBS2 I often buy something I see in a store without planning, just because I got to have it

P-CBS3 Shopping is a way of relaxing and forgetting my problems

P-CBS4 I sometimes feel that something inside pushes me to go shopping

P-CBS5 There are times when I have strong urge to buy (clothing, tapes, jewelries etc.)

CBS1

CBS2

CBS3

CBS4

CBS5

P-CBS6 At times, I have felt somewhat guilty after CBS6 buying something because it seemed unreasonable

P-CBS7 There are some things I buy that I do not show to anybody because I fear people will think I did a foolish expense or I wasted money

P-CBS8 I often have a real desire to go shopping and buy something

P-CBS9 I have often bought a product that I did not need even when I knew I had very little money left

P-CBS10 I like to spend money

P-CBS11 As soon as I enter a shopping center, I wish to go in a store and buy something

The original Compulsive Buying Scale (CBS, d'Astous et al. 1990) and its translated version (P-CBS) along with scale items, measured on 5-point Likert scale with agree/disagree format of response answers $(1=$ totally disagree, $2=$ partially disagree, $3=$ neither disagree nor agree, $4=$ partially agree, $5=$ totally agree)

Item in italics was modified due to Polish cultural setting 


\section{References}

Baack, D., Boggs, D.: The differences in using a cost leadership strategy in emerging markets. Int. J. Emerg. Mark. 3(2), 125-139 (2008)

Bagozzi, R.P., Yi, Y.J.: On the evaluation of structural equation models. J. Acad. Mark. Sci. 16(1), 74-94 (1988)

Baker, A., Moschis, G.P., Rigdon, E., Kwaifatt, C.: Linking family structure to impulse control and obsessive-compulsive buying. J. Consum Behav 15(4), 291-302 (2016)

Bechtoldt, H.P.: Construct validity: a critique. Am. Psychol. 14, 619-629 (1959)

Belk, R.W.: Leaping luxuries and transitional consumers. In: Batra, R. (ed.) Marketing issues intransitional economies, pp. 38-54. Kluwer, Norwell (1999)

Billieux, J., Rochat, L., Rebetez, M.M.L., Van der Linden, M.: Are all facets of impulsivity related to selfreported compulsive buying behavior? Personal. Individ. Differ. 44(6), 1432-1442 (2008)

Blackwell, R.D., Miniard, P.W., Engel, J.F.: Consumer behavior. Fort Worth, Dryden (2001)

Bleuler, E.: Textbook of psychiatry. MacMillan, New York (1924)

Boski, P.: Culture consequences for market economy: stability of anti-materialist orientation in Polish mentality. In: Rudmin, F., Richins, M. (eds.) Meaning, measure, and morality of materialism, pp. 14-30. UT: Association for Consumer Research, Provo (1992)

Boski, P.: Humanism-materialism: centuries-long Polish cultural origins and 20 years of research. In: Kim, U., Yang, K.S., Hwang, K.-K. (eds.) Indigenous and Cultural Psychology: Understanding People in Context, pp. 373-402. Springer, New York (2006)

Brislin, R.W.: The wording and translation of research instruments. In: Lonner, W.J., Berry, J.W. (eds.) Cross-Cultural Research and Methodology Series. Field Methods in Cross-Cultural Research, pp. 137-164. Sage Publications, Thousand Oaks (1986)

Byrne, B.: Structural Equation Modeling with Mplus. Routledge, New York (2013)

Byrne, D.G., Davenport, S.C., Mazanov, J.: Profiles of adolescent stress: the development of the adolescent stress questionnaire (ASQ). J Adolesc 30(3), 393-416 (2007)

Carpenter, N.C., Son, J., Harris, T.B., Alexander, A.L., Horner, M.T.: Don't forget the items: item-level meta-analytic and substantive validity techniques for reexamining scale validation. Organ. Res. Methods. 9(4), 616-650 (2016)

Cattell, R.B.: Factor Analysis. Greenwood Press, Westport (1952)

Cheung, G.W., Rensvold, R.B.: Evaluating goodness-of-fit indexes for testing measurement invariance. Struct. Equ. Model. 9(2), 233-255 (2002)

Chitakunye, P., Maclaran, P.: Materiality and family consumption: The role of the television in changing mealtime rituals. Consum. Mark. Culture 17(1), 50-70 (2012)

Cho, E.: Making reliability reliable: a systematic approach to reliability coefficients. Organ. Res. Methods 19(4), 651-682 (2016)

Cicognani, E.: Coping strategies with minor stressors in adolescence: relationships with social support, selfefficacy, and psychological well-being. J. Appl. Soc. Psychol. 41(3), 559-578 (2011)

Claes, L., Bijttebier, P., Van Den Eynde, F., Mitchell, J.E., Faber, R., de Zwaan, M., Mueller, A.: Emotional reactivity and self-regulation in relation to compulsive buying. Personal. Individ. Differ. 49(5), 526-530 (2010)

Clark, L.A., Watson, D.: Constructing validity: basic issues in objective scale development. Psychol. Assess. 7(3), 309-319 (1995)

Cloutier, D.: The Vice of Luxury: Economic Excess in a Consumer Age. Georgetown University Press, Washington D.C. (2015)

Cole, L., Sherrell, D.: Comparing scales to measure compulsive buying: An exploration of their dimensionality. In: Kardes, F., Sujan, M. (eds.) Advances in Consumer Research, pp. 419-427. UT: Association for Consumer Research, Provo (1995)

Cronbach, L.J.: Coefficient alpha and the internal structure of tests. Psychometrika 16(3), 297-334 (1951)

d'Astous, A.: An inquiry into the compulsive side of normal consumers. J. Consum. Policy 13(1), 15-31 (1990)

d'Astous, A., Bellemare, Y.: Contrasting compulsive and normal buyers' reactions to image versus product quality advertising. In: d'Astous, A. (eds.) Proceedings of the Annual Conference of the Administrative Sciences Association of Canada. Marketing Division, pp. 82-91. Administrative Sciences Association of Canada, Montréal (1989)

d'Astous, A., Maltais, J., Roberge, C.: Compulsive buying tendencies of adolescentconsumers. In: Goldberg, M., Gorn, G., Pollay, W. (eds.) Advances in Consumer Research, pp. 306-312. UT: Association for Consumer Research, Provo (1990) 
Dittmar, H.: Compulsive buying: a growing concern? An examination of gender, age, and endorsement of materialistic values as predictors. Br. J. Psychol. 96(4), 467-491 (2005)

Edwards, E.A.: Development of a new scale for measuring compulsive buying behavior. Financial Couns. Plan. 4, 67-85 (1993)

Elliott, R.: Compulsive consumption: function and fragmentation in postmodernity. J. Consum. Policy 17(2), 159-179 (1994)

European Social Survey Report, downloaded 24.09.2019, at https://www.europeansocialsurvey.org/metho dology/ess_methodology/sampling.html; https://www.europeansocialsurvey.org/docs/round1/metho ds/ESS1_sampling_report.pdf

Eurostat: European Statistics. Downloaded 19.03.109, at https://ec.europa.eu/eurostat/en (2019)

Faber, R.J., O'Guinn, T.C.: Classifying compulsive consumers: advances in the development of a diagnostic tool. Adv. Consum. Res. 16, 738-744 (1989)

Faber, R.J., O'Guinn, T.C.: A clinical screener for compulsive buying. J. Consum. Res. 19(3), 459-690 (1992)

Faber, R.J., O’Guinn, T.C., Krych, R.: Compulsive consumption. Adv. Consum. Res. 5, 132-135 (1987)

Flight, R.L., Rountree, M.M., Beatty, S.E.: Feeling the urge: Affect in impulsive and compulsive buying. J. Mark. Theory Pract. 20(4), 453-466 (2012)

Ger, G., Belk, R.W.: I'd like to buy the world a coke: consumptionscapes of the less affluent world. J. Consum. Policy 19(3), 271-304 (1996)

Grougiou, V., Moschis, G.P.: Antecedents of young adults' materialistic values. J. Consum. Behav. 14(2), 115-126 (2015)

Grougiou, V., Kapoutsis, I., Moschis, G.P.: Compulsive buying: The role of earlier-in life events and experiences. J. Consum. Mark. 32(4), 278-289 (2015)

Hair, J.F., Black, W.C., Babin, B.J., Anderson, R.E.: Multivariate Data Analysis: A Global Perspective. Pearson Prentice Hall, London (2010)

Hampel, P., Peterman, F.: Perceived stress, coping, and adjustment in adolescents. J. Adolesc. Health 38(4), 315-409 (2006)

Hassay, D.N., Smith, M.: Compulsive buying: An examination of the consumption motive. Psychol. Mark. 13(8), 741-752 (1996)

He, H., Kukar-Kinney, M., Ridgway, N.M.: Compulsive buying in China: measurement, prevalence, and online drivers. J. Bus. Res. 91, 28-39 (2017)

Hill, M.S., Yeung, W.J., Duncan, G.J.: Childhood family structure and young adult behaviors. J. Popul. Econ. 14(2), 271-299 (2001)

Hofstede, G.: Culture's Consequences: Comparing Values, Behaviors, Institutions andOrganizations Across Nations. Sage Publications, Thousand Oaks (2001)

Horváth, C., van Herk, H., Adigüzel, F.: Cultural aspects of compulsive buying in emerging and developed economies: a cross cultural study in compulsive buying. Org. Mark. Emerg. Econ. 4(8), 8-24 (2013)

Hu, L.-T., Bentler, P.M.: Cutoff criteria for fit indexes in covariance structure analysis: conventional criteria versus new alternatives. Struct. Equ. Model. 6(1), 1-55 (1999)

Hubert, M., Hubert, M., Gwozdz, W., Raab, G., Reisch, L.: Compulsive buying: an increasing problem? Investigating and comparing trends in Germany and Denmark, 2010-2012. J Consum. Prot. Food Saf. 9(3), 280-284 (2014)

Ibroscheva, E.: The unbearable lightness of advertising: culture, media and the rise of advertising in Socialist Bulgaria. Consum. Mark. Cult. 16(3), 290-310 (2012)

Johnson, H.D., Lavoie, J.C., Mahoney, M.: Interparental conflict and family cohesion: predictors of loneliness, social anxiety, and social avoidance in late adolescence. J. Adolesc. Res. 16(3), 304-318 (2001)

Joireman, J., Kees, J., Sprott, D.: Concern with immediate consequences magnifies the impact of compulsive buying tendencies on college students' credit card debt. J Consum Aff. 44(1), 155-178 (2010)

Jöreskog, K.G.: Statistical analysis of sets of congeneric tests. Psychometrika 36(2), 109-133 (1971)

Keeley, M., Buehler, H.: Shopaholic stories: tales of therapeutic addiction, governance, and political economy. J Consum. Cult. 18(4), 497-519 (2016)

Khare, A.: Credit card use and compulsive buying behavior. J. Glob. Marketing 26(1), 28-40 (2013)

Kline, P.: A Handbook of Test Construction. Methuen, New York (1986)

Kline, R.B.: Promise and pitfalls of structural equation modeling in gifted research. In: Thompson, B., Subotnik, R.F. (eds.) Methodologies for Conducting Research on Giftedness, pp. 147-169. American Psychological Association, Washington, DC (2011)

Koran, L.M., Faber, R.J., Aboujaoude, E., Large, M.D., Serpe, R.T.: Estimated prevalence of compulsive buying behavior in the United States. Am. J. Psychiatry 163(10), 1806-1812 (2006) 
Kozminski, A.: Consumers in transition from the centrally planned economy to the market economy. J. Consum. Policy 14(4), 51-69 (1991)

Kraepelin, E.: Psychiatrie. Verlag von Johann Ambrosius Barth, Leipzig (1915)

Lam, S.C., Chan, Z.S.-L., Chong, A.C.-Y., Wong, W.W.-C., Ye, J.: Adaptation and validation of Richmond compulsive buying scale in Chinese population. J. Behav. Addict. 7(3), 760-769 (2018)

Larson, R.W.: How U.S. children and adolescents spend time: what it does (and doesn't) tell us about their development. Curr. Dir. Psychol. Sci. 10(5), 160-164 (2001)

Lejoyeux, M., Ades, J.: Les achats pathologiques: une addiction comportementale. Neuro-Psy 9, 25-32 (1994)

Lejoyeux, M., Mathieu, K., Embouazza, H., Huet, F.O., Lequen, V.R.: Prevalence of compulsive buying among customers of a Parisian general store. Compr. Psychiatry 48(1), 42-46 (2007)

Li, S., Unger, A., Bi, C.: Different facets of compulsive buying among Chinese students. J. Behav. Addict. 3(4), 238-245 (2014)

Lim, E.A.C., Ang, S.H.: Hedonic vs. utilitarian consumption: a cross-cultural perspective based on cultural conditioning. J Bus. Res. 61(3), 225-232 (2008)

Lo, H., Harvey, N.: Shopping without pain: compulsive buying and the effects of credit card availability in Europe and the far east. J. Econ. Psychol. 32(1), 79-92 (2011)

Lu, J., Liu, Z., Fang, Z.: Hedonic products for you, utilitarian products for me. Judgm. Decis Mak. 11(4), 332-341 (2016)

Luthar, B.: Remembering socialism: on desire, consumption and surveillance. J. Consum. Cult. 6(2), 229259 (2006)

Lyons, B., Henderson, K.: An old problem in a new marketplace: Compulsive buying on the Internet. Paper presented at the ANZMAC 2000 Visionary Marketing for the 21st Century: Facing the Challenge, Australia (2000)

Manolis, C., Roberts, J.A.: Subjective well-being among adolescent consumers: the effects of materialism, compulsive buying, and time affluence. Appl. Res. Qual. Life 7(2), 117-135 (2012)

Maraz, A., Mark, D., Demetrovics, Z.: The prevalence of compulsive buying: meta-analysis". Addiction 111(3), 408-419 (2016)

Mazurek, M., Hilton, M.: Consumerism, solidarity and communism: consumer protection and the consumer movement in Poland. J. Contemp. Hist. 42(2), 315-343 (2007)

McElroy, S.L., Keck, P.E., Jr., Pope, H.G., Jr., Smith, J.M.R., Strakowski, S.M.: Compulsive buying: a report of 20 cases. J. Clin. Psychiatry 55, 242-248 (1994)

Mick, D.G., Broniarczyk, S.M., Haidt, J.: Choose, choose, choose, choose, choose, choose, choose: emerging and prospective research on the deleterious effects of living in consumer hyperchoice. J. Bus. Ethics 52(2), 207-211 (2004)

Mueller, A., Mitchell, J.E., Crosby, R.D., Gefeller, O., Faber, R.J., Martin, A., Bleich, S., Glaesmer, H., Exner, C., de Zwaan, M.: Estimated prevalence of compulsive buying in Germany and its association with sociodemographic characteristics and depressive symptoms. Psychiatry Res. 180(2), 137-142 (2010)

Mueller, A., Claes, L., Mitchell, J.E., Faber, R.J., Fischer, J., de Zwaan, M.: Does compulsive buying differ between male and female students? Personal. Individ. Differ. 50(8), 1309-1312 (2011)

Müller, A., Trotzke, P., Mitchell, J.A., de Zwaan, M., Brand, M.: The pathological buying screener: development and psychometric properties of a new screening instrument for the assessment of pathological buying symptoms. PLoS ONE (2015). https://doi.org/10.1371/journal.pone.0141094

Neuner, M., Raab, R., Reisch, L.A.: Compulsive buying in maturing consumer societies: an empirical reinquiry. J. Econ. Psychol. 26(4), 509-522 (2005)

Nevo, B.: Face validity revisited. J. Educ. Meas. 22(4), 287-293 (1985)

Nunnally, J.C.: Psychometric Theory. McGraw-Hill, New York (1978)

O'Guinn, T.C., Faber, R.J.: Compulsive buying: a phenomenological exploration. J. Consum. Res. 16(2), 147-157 (1989)

O'Shaughnessy, J., O'Shaughnessy, N.J.: Marketing, the consumer society and hedonism. Eur. J. Mark. 36(5/6), 524-547 (2002)

Central Statistical Office in Poland: Demographic Yearbook of Poland - 2018. (downloaded at https://stat. gov.pl/en/topics/population/ (2018)

Otero-López, J.M., Villardefrancos, E.: Prevalence, sociodemographic factors, psychological distress, and coping strategies related to compulsive buying: a cross-sectional study in Galicia, Spain. BMC Psychiatry 14, 101 (2014)

Palan, K.M., Morrow, P.C., Trapp, A., Blackburn, V.: Compulsive buying behavior in college students: the mediating role of credit card misuse. J Mark. Theory Pract. 19(1), 81-96 (2014) 
Podsakoff, P.M., MacKenzie, S.B., Lee, J.-Y., Podsakoff, N.P.: Common method biases in behavioral research: a critical review of the literature and recommended remedies. J. Appl. Psychol. 88(5), 879903 (2003)

Podsakoff, P.M., MacKenzie, S.B., Podsakoff, N.P.: Sources of method bias in social science research and recommendations on how to control it. Annu. Rev. Psychology 63(1), 539-569 (2012)

Raab, G., Neuner, M., Reisch, L.A., Scherhorn, G.: Screeningverfahren zur Erhebung von kompensatorischem und süchtigem Kaufverhalten (SKSK). Hogrefe, Göttingen (2005)

Reisch, L.A., Neuner, M.: Women and addictive buying: The gender question revisited. In: Ureta, G., Fernandez, E.O. (eds.) El consumo y la ddiccion a las compras: Diferentes perspectivas, pp. 169-195. The University of the Basque Country Press, Bilbao (2002)

Richins, M.L., Chaplin, L.N.: Material parenting: how the use of goods in parenting fosters materialism in the next generation. J. Consum. Res. 41(6), 1333-1357 (2015)

Ridgway, N.M., Kukar-Kinney, M., Monroe, K.B.: An expanded conceptualization and a new measure of compulsive buying. J. Consum. Res. 35(4), 622-639 (2008)

Ritzer, G., Jurgenson, N.: Production, consumption, prosumption: the nature of capitalism in the age of the digital 'prosumer.' J. Consum. Cult. 10(1), 13-36 (2010)

Roberts, J.A.: Consuming in a consumer culture: college students, materialism, status consumption, and compulsive buying. Mark. Manag. J. 10(2), 76-91 (2000)

Roberts, J.A., Jones, E.: Money attitudes, credit card use, and compulsive buying among American college students. J. Consum. Aff. 35(2), 314-340 (2001)

Roberts, J.A., Martinez, C.R.: The emerging consumer culture in Mexico: an exploratory investigation of compulsive buying in Mexican young adults. J. Int. Consum. Mark. 10(1-2), 7-31 (1997)

Roberts, J.A., Roberts, C.: Stress, gender and compulsive buying among early adolescents. Young Consum. 13(2), 113-123 (2012)

Roberts, J.A., Sepulveda, C.J.M.: Money attitudes and compulsive buying: an exploratory investigation of the emerging consumer culture in Mexico. J. Int. Consum. Mark. 11(4), 53-74 (1999)

Scherhorn, G., Reisch, L.A., Raab, G.: Addictive buying in West Germany: an empirical study. J. Consum. Policy 13(4), 355-388 (1990)

Scherhorn, G., Reisch, L.A., Raab, G.: Addictive buying. Further investigations in West and East Germany. In: Paper presented at the Joint Conference on Economic Psychology and Experimental Economics, Frankfurt am Main, Germany, 27-30 August 1992 (1992)

Schlosser, S., Black, D.W., Repertinger, S., Freet, D.: Compulsive buying: demography, phenomenology, and comorbidity in 46 subjects. Gen. Hosp. Psychiatry 16(3), 205-212 (1994)

Shevlin, M., Miles, J.N.V., Davies, M.N.O., Walker, D.S.: Coefficient alpha: a useful indicator of reliability? Personal. Individ. Differ. 28(2), 229-237 (2000)

Singh, R., Nayak, J.K.: Life stressors and compulsive buying behaviour among adolescents in India. South Asian J. Glob. Bus. Res. 4(2), 251-274 (2015)

Tarka, P., Kukar-Kinney, M.: Compulsive buying in Eastern Europe. Journal of Consumer Marketing, in press. (2020)

Tobacyk, J.J., Babin, B.J., Attaway, J.S., Socha, S., Shows, D., James, K.: Materialism through the eyes of Polish and American consumers. J. Bus. Res. 63, 944-960 (2011)

Tomer, J.F.: Addictions are not rational: a socio-economic model of addictive behavior. J. Socio-Economics 33, 243-261 (2001)

Valence, G., d'Astous, A., Fortier, L.: Compulsive buying: concept and measurement. J. Consum. Policy 11(4), 419-433 (1988)

Varman, R., Vikas, R.M.: Freedom and consumption: toward conceptualizing systemic constraints for subaltern consumers in a capitalistic society. Consum. Mark. Cult. 10(2), 117-131 (2007)

Vihalemm, T., Keller, M.: Looking Russian or Estonian; young consumers constructing the ethnic "self" and "other." Consum. Mark. Cult. 14(3), 293-309 (2011)

Werts, C.E., Rock, D.R., Linn, R.L., Jöreskog, K.G.: A general method of estimating the reliability of a composite. Educ. Psychol. Measur. 38(4), 933-938 (1978)

Wieland, A., Durach, C.F., Kembro, J., Treiblmaier, H.: Statistical and judgmental criteria for scale purification. Supply Chain Manag.: Int. J. 22(4), 321-328 (2017)

Workman, L., Paper, D.: Compulsive buying: a theoretical framework. J Bus Enq 9(1), 89-126 (2013)

Yuengert, A.M.: Rational choice with passion: Virtue in a model of rational addiction. Unpublished paper. Pepperdine University, Malibu, California (1997)

Yurchisn, J., Johnson, K.K.P.: Compulsive buying behavior and its relationship to perceived social status associated with buying, materialism, self-esteem, and apparel-product involvement. Fam. Consum. Sci. Res. J. 32, 291-314 (2004) 
Zalewska, J.: Consumer revolution in people's Poland: technologies in everyday life and the negotiation between custom and fashion (1945-1980). J. Consum. Cult. 17(2), 321-339 (2016)

Zhang, W.: Consumption, taste, and the economic transition in modern China. Consum. Mark. Cult. (2018). https://doi.org/10.1080/10253866.2018.1467316

Zhang, J.W., Howell, R.T., Howell, C.J.: Living in wealthy neighborhoods increases material desires and maladaptive consumption. J. Consum. Cult. 16(1), 297-316 (2014)

Publisher's note Springer Nature remains neutral with regard to jurisdictional claims in published maps and institutional affiliations. 